\title{
23. MINERALOGY AND DIAGENESIS: THEIR EFFECT ON ACOUSTIC AND ELECTRICAL PROPERTIES OF PELAGIC CLAYS, DEEP SEA DRILLING PROJECT LEG 86 ${ }^{1}$
}

\author{
J. Schoonmaker, F. T. Mackenzie, M. Manghnani, R. C. Schneider, D. Kim, A. Weiner, and J. To, \\ University of Hawaii ${ }^{2}$
}

\begin{abstract}
Analysis of pelagic clay samples from Sites 576,578 , and 581 shows that physical, acoustic, and electrical trends with increasing burial depth are related to mineralogical and diagenetic changes. The properties of interest are bulk density $(\rho)$, porosity $(\Phi)$, compressional-wave velocity $\left(V_{\mathrm{p}}\right)$ and velocity anisotropy $\left(A_{\mathrm{p}}\right)$, and electrical resistivity $\left(R_{\mathrm{o}}\right)$ and resistivity anisotropy $\left(A_{\mathrm{r}}\right)$. In general, as demonstrated in particular for the brown pelagic clay, the increase in $\rho, V_{\mathrm{p}}, R_{\mathrm{o}}$, and to a lesser extent $A_{\mathrm{p}}$ and $A_{\mathrm{r}}$, with increasing depth is primarily caused by decreasing $\Phi$ (and water content) as a result of compaction.

The mineralogy and chemistry of the pelagic clays vary as a function of burial depth at all three sites. These variations are interpreted to reflect changes in the relative importance of detrital and diagenetic components. Mineralogical and chemical variations, however, play minor roles in determining variations in acoustic and electrical properties of the clays with increasing burial depth.
\end{abstract}

\section{INTRODUCTION}

This chapter is part of a continuing effort to relate sedimentary and diagenetic conditions of deposition and lithification of sediments to the physical, acoustic, and electrical properties of the sediments (e.g., Manghnani, et al., 1980). Our main purpose is to develop predictive physical-property models of sediment sequences in ocean basins and to correlate these with available seismic measurements. Both geological and geophysical approaches must be applied to the development of predictive models for ocean sediment. By a predictive model we mean one in which the important geophysical parameters, namely density $(\rho)$, porosity $(\Phi)$, compressional velocity $\left(V_{\mathrm{p}}\right)$, shear velocity $\left(V_{s}\right)$, Poisson's ratio $(\sigma)$, velocity anisotropy $\left(A_{\mathrm{p}}, A_{\mathrm{s}}\right)$, attenuation $\left(Q_{\mathrm{p}}^{-1}, Q_{\mathrm{s}}^{-1}\right)$, electrical resistivity $\left(R_{\mathrm{o}}\right)$, and resistivity anisotropy $\left(A_{\mathrm{r}}\right)$, can be estimated along a depth axis in a sediment sequence between the seafloor and the basaltic basement for a given latitude and longitude. These geophysical parameters are a function of the sedimentologic, paleoceanographic, and diagenetic processes leading to the formation of these sediment sequences.

In this chapter, laboratory measurements are reported for density, compressional velocity and velocity anisotropy, resistivity and resistivity anisotropy, chemistry, and mineralogy of Leg 86 sediment samples, particularly pelagic clays. Although values for some of these parameters are reported elsewhere in this volume, our purpose was to determine physical, chemical, and mineral-

\footnotetext{
${ }^{1}$ Heath, G. R., Burckle, L. H., et al., Init. Repts. DSDP, 86: Washington (U.S. Govt. Printing Office).

2 Addresses: (Schoonmaker) Hawaii Institute of Geophysics, University of Hawaii, Honolulu, HI 96822; (Mackenzie) Hawaii Institute of Geophysics and Department of Oceanography, University of Hawaii, Honolulu, HI 96822; (Manghnani) Hawaii Institute of Geophysics and Department of Geology and Geophysics, University of Hawaii, Honolulu, HI 96822; (Schneider) Department of Oceanography, University of Hawaii, Honolulu, HI 96822; (Kim. Weiner, To) Department of Geology and Geophysics, University of Hawaii, Honolulu, HI 96822 .
}

ogical properties by a cooperative group of investigators in the same laboratory on the same samples. Some measurements, such as shear velocity, are still in progress at the time of this writing. The measured geophysical parameters of the sedimentary sequences at Deep Sea Drilling Project (DSDP) Sites 576, 578, and 581 are evaluated in light of sediment burial depth (compaction), age, and diagenetic stage as interpreted from sediment chemistry and mineralogy. Emphasis is placed on the pelagic clay within these sequences.

On Leg 86, a series of sites were sampled in the Northwest Pacific Basin, which is essentially an abyssal plain removed from significant riverine terrigenous sediment input (Fig. 1). Hydraulic piston coring at Site 576 was designed to sample the regional, laterally uniform, surface, acoustically "transparent" layer for studies of the origin and geotechnical properties of the pelagic clay making up the layer. Hole 576 penetrated a $55-\mathrm{m}$ section of Tertiary pelagic clay underlain by Cretaceous interbedded calcareous ooze and pelagic clay (Fig. 2). The "type" pelagic clay section can be subdivided into two subunits, the upper having a considerable eolian component and the lower having a significant authigenic component (see Site 576 chapter, this volume).

Holes 578 and 581 penetrated thicker sections of Tertiary pelagic sediment, including interbedded siliceous clay, volcanic ash, and "type" pelagic clay overlying Cretaceous chert. Hole 578 was sampled by hydraulic piston coring; Hole 581 was cored using conventional rotary drilling methods. The fact that all three holes penetrated a section of relatively homogeneous pelagic clay, termed "slick" in the initial DSDP Hole Summary (unpublished data), is of particular interest. This unit is found at increasing stratigraphic depth from Site 576 to 578 to 581 . Thus, it is a particularly useful horizon for study of the effects of physical compaction on acoustic and electrical properties, as opposed to effects of sediment mineralogy and diagenesis. It was anticipated that 


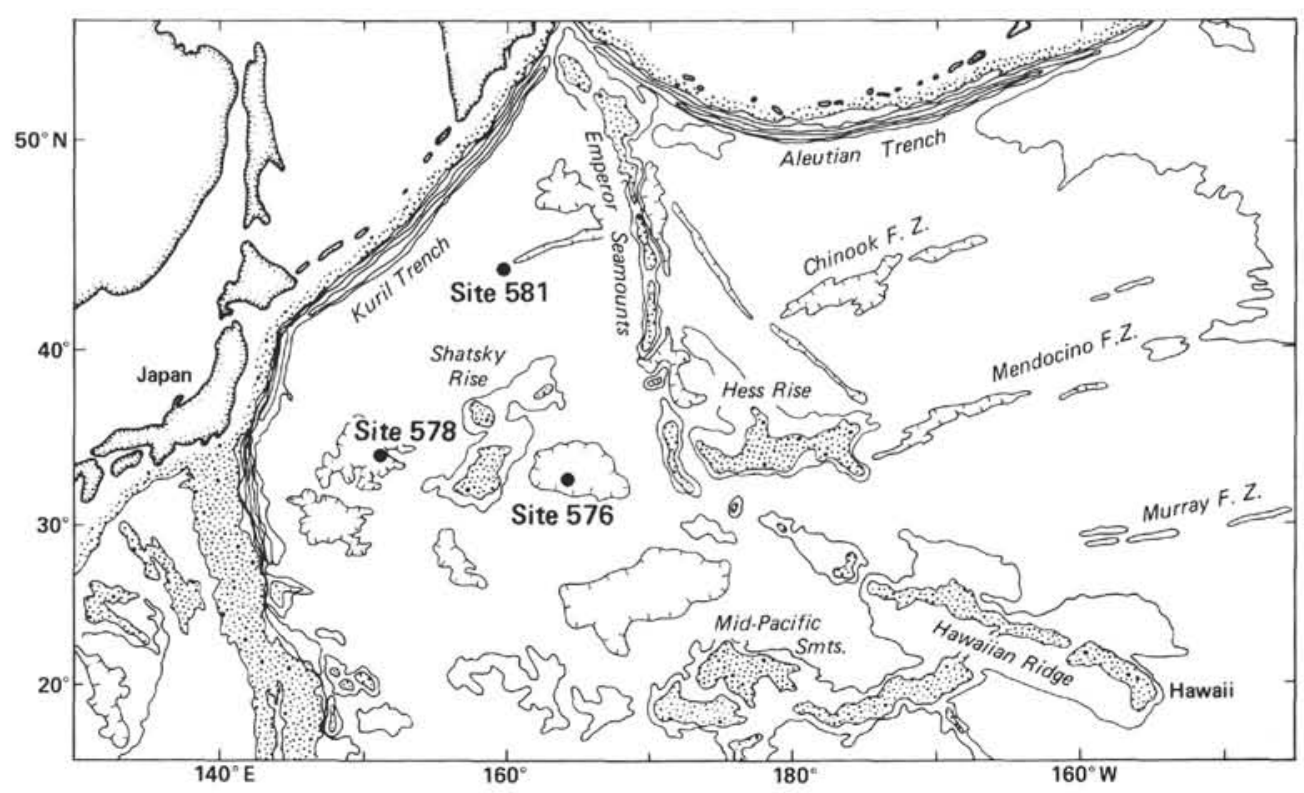

Figure 1. Location of Sites 576, 578, and 581 visited during DSDP Leg 86.

the sedimentary sequences of Holes 576,578 , and 581 , including the "slick" clay layer, might be dominated by eolian and current-transported fine-grained detritus. If so, the "slick" pelagic clay would be an ideal unit to determine the effects of simple compaction on deep-sea muds. To our knowledge, there are no hiatuses within the sediment sequences studied that could complicate the interpretation of depth trends as discussed in this chapter.

It is generally known that the porosity of sediment increases with decreasing grain size. As shown by Hamilton et al. (1982) for pelagic and hemipelagic sediments, this relationship shows a large amount of scatter. This scatter is due to other factors (e.g., sorting, grain shape, grain packing, and mineralogy) that are interrelated and that all influence porosity. It appears that the primary reason for the high initial porosity of muds is their microstructure or fabric. In clay-rich sediments, clay mineral platelets adhere to one another in a face-to-face arrangement forming books or packets. Depending on the amount of clay, the initial sediment depositional fabric will vary somewhat. In most hemipelagic and pelagic mudstones, however, the plates, packets, and clay flocs will be randomly oriented and interlinked in a "house of cards" fashion leading to initially high porosities. Upon burial and compaction, the links or chains between clay packets fail and the particles orient under the overburden pressure with long axes normal to pressure. This preferred orientation of clay minerals with increasing burial depth should lead to increasing anisotropy in acoustic velocity and electrical resistivity of the sediment with increase in depth.

It will be shown that the mineralogy and chemistry of the sedimentary sequences of Holes 576, 578, and 581 vary with burial depth and that there is evidence for diagenetic reactions occurring, particularly in the "slick" clay zone. Regardless, it appears that most variations in the acoustic and electrical properties of the pelagic clay can be attributed to compactional effects such as reorganization of clay platelets.

\section{METHODS}

\section{Sampling}

The cores were sampled by cutting a $50-\mathrm{cm}^{3}$ piece from the center of the working half of the core. The samples were extracted with spatulas, wrapped carefully with plastic wrap, and stored in sealed bags with wet sponges to prevent dehydration. In our laboratory, cubes were cut for acoustic and electrical property measurements. The trimmings from these cubes were used to determine chemistry and mineralogy.

Samples were taken at intervals of 5 to $10 \mathrm{~m}$ in Hole 576 . The calcareous oozes from the hole were not sampled. Four samples were taken from the upper $110 \mathrm{~m}$ of Hole 578; the remainder of the hole was sampled at 5- to $10-\mathrm{m}$ intervals. Three samples were taken from the pelagic clay of Hole 581 .

\section{Mineralogy}

Mineralogy was determined by X-ray diffraction. Samples for bulk mineralogy were dried at $70^{\circ} \mathrm{C}$ for $24 \mathrm{hr}$., gently crushed to homogeneity, and packed into an aluminum holder. For clay mineralogy, samples were first treated with $5 \%$ sodium hypochlorite (Chlorox) buffered to $\mathrm{pH} 9.5$ with $\mathrm{HCl}$ to remove organic matter (Anderson, 1963). The less than $2-\mu \mathrm{m}$ fraction was then separated by centrifugation. A slurry of the sample was settled on a glass slide and dried at room temperature to produce an oriented sample. These slides were placed in an ethylene glycol atmosphere at $40^{\circ} \mathrm{C}$ for $24 \mathrm{hr}$. prior to X-ray diffraction to insure full expansion of expandable clay minerals. An additional aliquot of the $<2-\mu \mathrm{m}$ sample was treated to remove amorphous Fe-oxyhydroxides with the Na citrate-Na dithionite method of Mehra and Jackson (1960). The presence of amorphous Fe-oxyhydroxides has been shown to interfere with detection of clay minerals by X-ray diffraction, especially at very low $2 \theta$ angles (Risvet, 1978). Slides were prepared and glycolated as described above. All samples were analyzed on a Phillips Norelco X-ray diffractometer using Ni-filtered, CuK $\alpha$ radiation. Samples were scanned from 2 to $32^{\circ} 2 \theta$ at a rate of $2^{\circ} 2 \theta / \mathrm{min}$. The $>2-\mu \mathrm{m}$ fraction of selected samples was analyzed for zeolites, and the $>20-\mu \mathrm{m}$ fraction of a few samples was analyzed for feldspars by X-ray diffraction. To distinguish kaolinite and chlorite, and palygorskite and illite, samples were scanned at $1 / 4^{\circ} 2 \theta / \mathrm{min}$. over the intervals $23-26^{\circ} 2 \theta$ and $7-10^{\circ} 2 \theta$, respectively. Smectite, identified by its $17-\AA$ ( 001$)$ peak and the series of higher order peaks, was found in all cases to contain interlayered illite. It is therefore referred to as mixed-layer illite/smectite, or simply illite/smectite. 


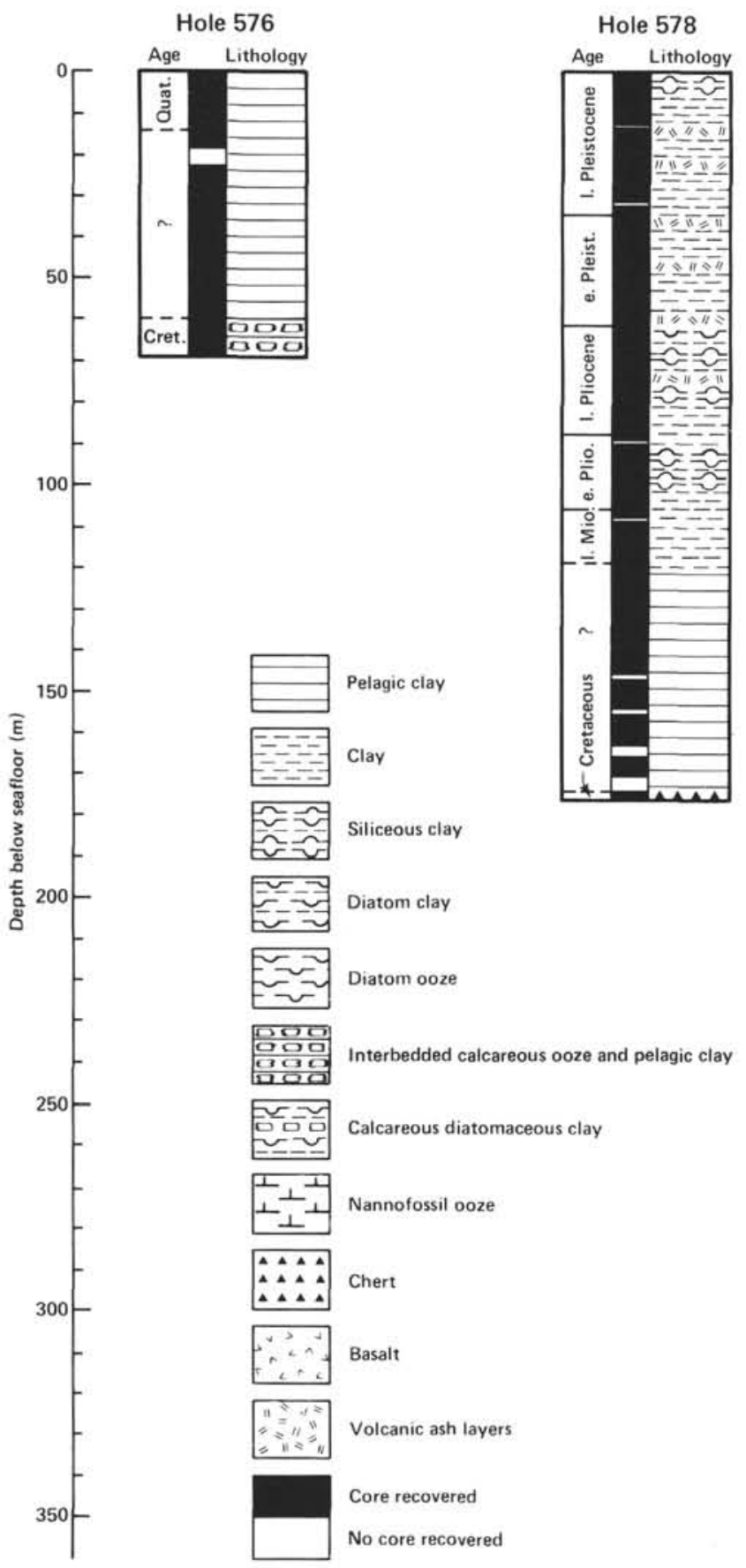

Hole 581

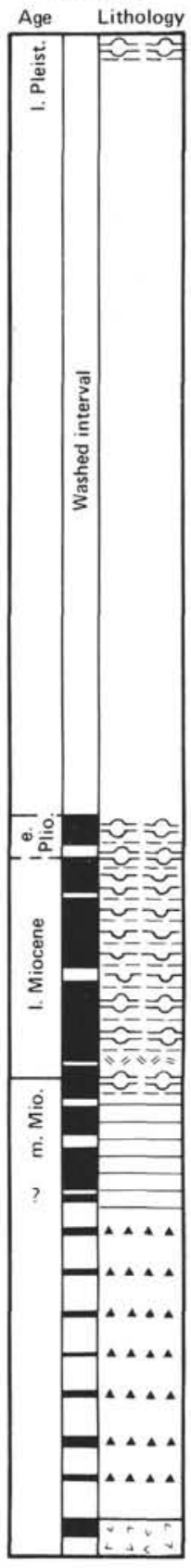

Figure 2. Age, core recovery, and lithostratigraphy for Holes 576, 578, and 581 (adapted from Introduction and Explanatory Notes, this volume).

Semiquantitative analysis of bulk-mineral composition followed the method of Schultz (1964). Using peak heights, and the factors for quartz, plagioclase $+\mathrm{K}$-feldspar, total clay, and clinoptilolite, the sum of these components was normalized to $100 \%$. Minor constituents omitted from this calculation included halite (from seawater contamination) and pyroxenes.

Clay-mineral abundances were calculated from peak areas measured by "the triangle method" of Mann and Fischer (1982). The weighting factors of Mann and Müller (1979) were used, and the weighted areas of all clay peaks were summed to $100 \%$. Quartz peaks, present in every sample, were omitted in this calculation, as was clinoptilolite which was present in one sample. The percentages of kaolinite and chlorite were determined by measuring the peak area at $12.3^{\circ} 2 \theta$ (kaolinite 001 , chlorite 002), and using the peak heights at $24.9^{\circ} 2 \theta$ (kaolinite 002 ) and $25.2^{\circ} 2 \theta$ (chlorite 003 ) to assess the relative contribution of the two minerals (Biscaye, 1965; Mann and Müller, 1979).

The abundances of mixed-layer illite/smectite, discrete illite, and the summation of kaolinite + chlorite were also determined by the method of Hoffman (1976). In this method, peak heights rather than areas are used. In addition, the intensity of the illite/smectite 003/005 peak at about $3.35 \AA$, corrected using an empirical relationship between intensity and mixed-layer composition, is used to estimate percent mixed-layer clay. This is in contrast to the method of Mann and Müller (1979), which uses the area of the (001) smectite peak and a weighting factor which is a linear combination of the individual illite and smectite factors. Composition of the mixed-layer illite/smectite was determined by the methods of Hoffman (1976) and Reynolds and Hower (1970). 


\section{Chemistry}

Bulk samples $(2.5 \mathrm{~g})$ were dried $\left(70^{\circ} \mathrm{C}, 24 \mathrm{hr}\right.$.), ground to a homogeneous powder, and rinsed and centrifuged three times in distilled water to remove sea-salt contamination. Major and trace elements (except silicon) were analyzed by inductively coupled plasma (ICP) after hydrofluoric-acid digestion. Silicon was analyzed by ICP after fusion with lithium metaborate.

\section{Scanning Electron Microscopy}

Pieces of bulk untreated samples were dried $\left(70^{\circ} \mathrm{C}, 24 \mathrm{hr}\right.$ ), and small fragments were broken off to reveal fresh surfaces. These were mounted on scanning electron microscopy (SEM) sample holders and coated with carbon and gold-palladium before analysis.

\section{Physical Properties}

\section{Bulk Density}

The bulk densities of the sediments were determined from their weights and volumes. Sediment samples were cut by a slow-speed saw and ground to well-shaped cuboids with three sets of parallel faces for ultrasonic velocity measurements. The three dimensions of the cuboid were measured with a vernier gauge or micrometer to an accuracy of $0.001 \mathrm{~cm}$.

\section{Ultrasonic Velocity Measurements}

The pulse-transmission technique (Birch, 1960) was used to measure compressional-wave velocities of the sediment. The apparatus, similar to the Hamilton-frame system (Boyce, 1976), consisted of a pulse generator, amplifier, and filter. A calibrated mercury delay line was used to measure transmission time of pulses in the specimen. $1-\mathrm{MHz}$ lead zirconium titanate (PZT-4) transducers mounted in holders were placed against the sediment surfaces. Dow Resin 276-V9 was used as the acoustic coupler. A small weight $(25 \mathrm{~g})$ was placed on the transducer holder to provide good acoustic contact. The reported compressional velocity values are accurate to $\pm 2 \%$.

\section{Electrical Resistivity}

The four-electrode resistivity method (Olhoeft, 1980), which has the advantage of eliminating electrode electrochemical polarization, was used for electrical resistivity measurements. Current leakage around the saturated sample was prevented by proper jacketing. The plexiglas sample holder was rectangular in shape to allow measurements of cuboid specimens. Two pairs of faces parallel and one pair of faces perpendicular to the bedding plane were prepared.

The resistivity of saturated samples (as received) was measured at $100 \mathrm{~Hz}$ with the Hewlett-Packard 4375B LCR meter. The applied current density was in the range $10^{-8}$ to $10^{-9} \mathrm{amp} / \mathrm{m}^{2}$, within the linear range of measurement. The sensitivity of the resistivity measurements is up to three decimal places. The measured values are reproducible to $\pm 5 \%$.

\section{DATA}

\section{Mineralogy}

\section{Bulk Mineralogy}

The pelagic clays of Sites 576, 578, and 581 are broadly similar in mineralogy and consist of varying amounts of clay minerals (mixed-layer illite/smectite, discrete illite, kaolinite, chlorite), quartz, feldspar, frequent palygorskite, rare zeolites, and amorphous material, probably primarily opaline silica. The quantitative bulk mineralogy, determined by X-ray diffraction, is given in Table 1; plots versus depth of percent total clay minerals, quartz, and feldspar are shown in Figure 3, and plots versus depth of clay to quartz ratio are shown in Figure 4. All depths for Hole 576 have been corrected following the format given in the Site 576 chapter (this volume).

Table 1. Mineralogy as determined by $\mathrm{x}$-ray diffraction of bulk samples from DSDP Holes 576,578 , and 581 .

\begin{tabular}{|c|c|c|c|c|c|c|c|}
\hline $\begin{array}{c}\text { Sample } \\
\text { (interval in } \mathrm{cm} \text { ) }\end{array}$ & $\begin{array}{l}\text { Sub-bottom } \\
\text { depth } \\
\text { (m) }\end{array}$ & $\begin{array}{l}\text { Total } \\
\text { clay } \\
(\%)\end{array}$ & $\begin{array}{c}\text { Quartz } \\
(\%)\end{array}$ & $\begin{array}{c}\text { Feldspar } \\
(\%)\end{array}$ & $\begin{array}{c}\text { Clinop- } \\
\text { tilolite } \\
(\%)\end{array}$ & $\begin{array}{l}\text { Phil- } \\
\text { lipsite }\end{array}$ & $\begin{array}{c}\text { X-ray } \\
\text { amorphous } \\
\text { material }\end{array}$ \\
\hline $576-1-1,46-50$ & $4.96-5.00$ & 65 & 25 & 10 & & & $\mathrm{x}$ \\
\hline $576-2-1,109-116$ & $8.29-8.36$ & 74 & 19 & 7 & & & $\mathrm{x}$ \\
\hline $576-2-6,99-106$ & $15.69-15.76$ & 71 & 21 & 8 & & & $\mathrm{x}$ \\
\hline $576-3-3,109-115$ & $13.69-13.75$ & 69 & 22 & 9 & & & $\mathrm{x}$ \\
\hline $576-4-2,88-95$ & $21.48-21.55$ & 76 & 18 & 6 & & & \\
\hline $576-4-5,98-104$ & $26.08-26.14$ & 76 & 17 & 7 & & & \\
\hline $576-5-1,108-115$ & $29.28-29.35$ & 77 & 16 & 7 & & & \\
\hline $576-5-6,18-25$ & $32.78-32.85$ & 80 & 11 & 10 & & $\mathrm{x}$ & $\mathrm{x}$ \\
\hline $576-6-4,37-44$ & $36.27-36.34$ & 86 & 9 & 5 & & & \\
\hline $576-7-2,130-137$ & $46.90-46.97$ & 85 & 10 & 6 & & & \\
\hline $576-7-6,19-26$ & $51.79-51.86$ & 83 & 11 & 6 & & & \\
\hline $576-8-1,98-105$ & $55.08-55.15$ & 82 & 11 & 7 & & & \\
\hline $576-8-6,81-84$ & $62.41-62.44$ & 85 & 10 & 6 & & & \\
\hline $578-2-4,38-45$ & $9.68-9.75$ & 65 & 20 & 15 & & & $\mathrm{x}$ \\
\hline $578-5-3,91-98$ & $37.21-37.28$ & 71 & 19 & 10 & & & $\mathrm{x}$ \\
\hline $578-10-3,91-98$ & $87.71-87.78$ & 70 & 21 & 9 & & & $\mathrm{x}$ \\
\hline $578-13-1,78-85$ & $110.08-110.15$ & 73 & 19 & 8 & & & $\mathrm{x}$ \\
\hline $578-14-4,53-60$ & $123.83-123.90$ & 79 & 15 & 6 & & & $x$ \\
\hline $578-15-2,53-60$ & $130.33-130.40$ & 80 & 13 & 7 & & & $x$ \\
\hline $578-15-7,28-34$ & $137.58-137.64$ & 81 & 13 & 6 & & & \\
\hline $578-16-5,67-74$ & $144.47-144.54$ & 84 & 10 & 6 & & & $\mathrm{x}$ \\
\hline $578-17-2,72-79$ & $149.52-149.59$ & 82 & 12 & 6 & & & $x$ \\
\hline $578-17-5,61-68$ & $153.91-153.98$ & 85 & 9 & 6 & & & \\
\hline $578-18-3,38-45$ & $160.18-160.25$ & 81 & 14 & 5 & & & \\
\hline $578-19-1,57-64$ & $166.87-166.94$ & 82 & 12 & 6 & & & \\
\hline $578-19-3,53-60$ & $169.83-169.90$ & 81 & 14 & 6 & & & \\
\hline $581-8-5,65-72$ & $245.15-245.22$ & 83 & 11 & 6 & & & \\
\hline $581-9-4,33-40$ & $252.83-252.90$ & 81 & 10 & 6 & 3 & & \\
\hline $581-10-3,44-51$ & $260.94-261.01$ & 83 & 11 & 6 & & & \\
\hline
\end{tabular}

Note: $\mathrm{x}$ indicates mineral is present. 


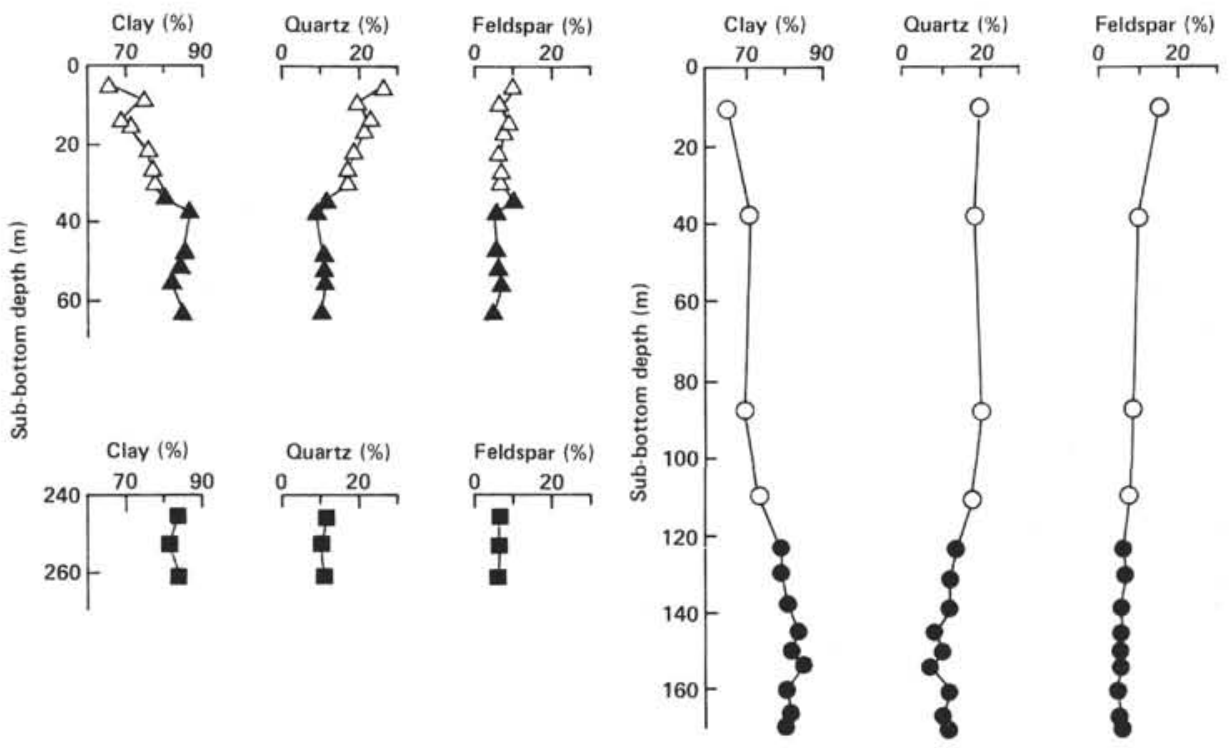

Figure 3. Bulk mineralogy of clay samples from Holes $576(\triangle), 578(\bigcirc)$, and $581(\square)$. Solid symbols indicate samples within the brown pelagic clay unit defined in the discussion section.

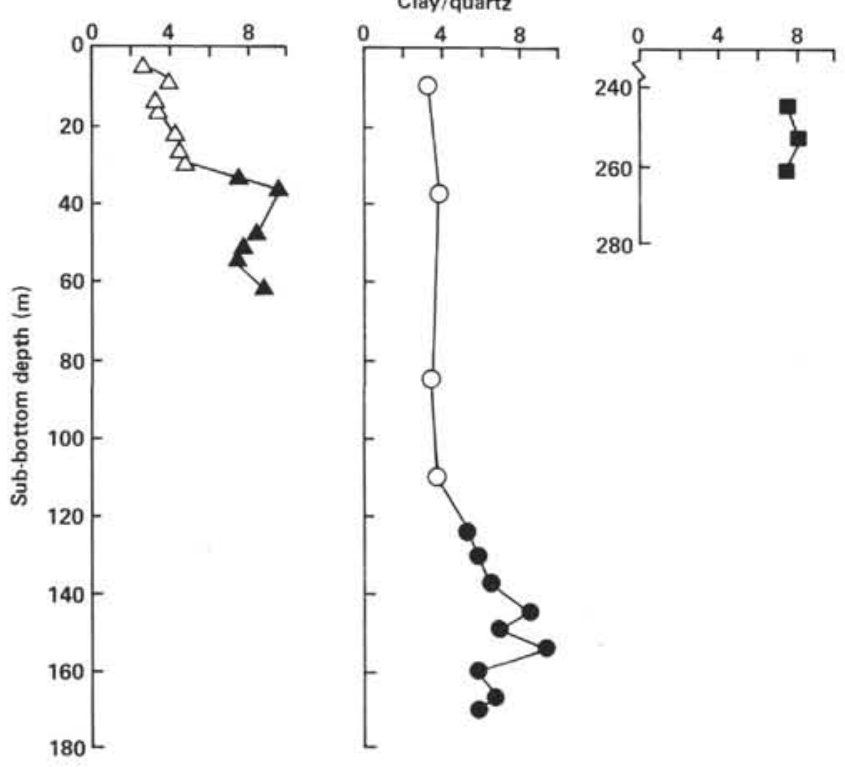

Figure 4. Clay/quartz ratios of samples collected from DSDP Holes 576, 578, and 581. Symbols as in Figure 3.

Scanning-electron photomicrographs illustrating some of the minerals and their textures are shown in Plate 1.

Total clay-mineral contents of samples from Holes 576 and 578 increase with depth from near-surface values of $\sim 65 \%$ to high values of $80-85 \%$ at depth (Fig. 3). Quartz and feldspar contents vary inversely with clay mineral content. Near-surface pelagic clay samples contain about $20 \%$ quartz and between 8 and $15 \%$ feldspar, whereas the deeper pelagic clays generally contain about $10-12 \%$ quartz and 5-6\% feldspar. The three samples analyzed from Hole 581 have bulk mineralogies very similar to samples from the deeper portions of Holes 576 and 578; that is, they are rich in clay minerals and poor in quartz and feldspar (Fig. 3). The depth trends of the clay/quartz ratios for the three sites (Fig. 4) emphasize the bulk mineralogical differences between pelagic clays of the upper and lower parts of the sites.

\section{Clay Mineralogy}

Mineralogies of the $<2-\mu \mathrm{m}$ size fraction of the samples are given in Table 2 . We report the data for the samples from which amorphous Fe-oxyhydroxides were not removed to facilitate comparison of our results with those of other workers, the majority of whom do not remove amorphous iron compounds. The effect of Fe removal will be discussed later. Figures 5, 6, and 7 show the trends with depth of the relative amounts of the clay minerals (mixed-layer illite/smectite, illite, kaolinite, chlorite, and palygorskite) normalized to $100 \%$. Although the amounts of non-clay minerals were not determined quantitatively, it is important to note that significant amounts of quartz and lesser amounts of feldspar are present in virtually every $<2-\mu \mathrm{m}$ sample (see Table 2 ).

$\mathrm{X}$-ray diffractograms were quantified using two methods. The solid lines in Figures 5, 6, and 7 indicate the values obtained using measured peak areas and the factors of Mann and Müller (1979). These are also the data given in Table 2. The dashed lines for percent illite/ smectite and illite in Figures 5, 6, and 7 indicate data obtained by using the quantification technique of Hoffman (1976), modified to account for the presence of quartz in the clay samples. Depth trends obtained by using the two methods are generally quite similar, although the Hoffman technique usually results in lower estimates of percent mixed-layer illite/smectite.

Samples of the $<2-\mu \mathrm{m}$ fraction were also analyzed after amorphous Fe-oxyhydroxide removal. These patterns were quantified according to both the Mann and Müller (1979) and the Hoffman (1976) techniques and the results compared to those shown in Figures 5, 6, and 7. With very few exceptions, the removal of Fe-oxyhydroxides enhanced the illite/smectite peaks, resulting in 
Table 2. Mineralogy of the $<2-\mu \mathrm{m}$ size fraction.

\begin{tabular}{|c|c|c|c|c|c|c|c|c|c|c|c|}
\hline $\begin{array}{c}\text { Sample } \\
\text { (interval in } \mathrm{cm} \text { ) }\end{array}$ & $\begin{array}{l}\text { Sub-bottom } \\
\text { depth } \\
\text { (m) }\end{array}$ & $\begin{array}{l}\text { ML } \\
(\%)\end{array}$ & $\begin{array}{l}\text { Illite } \\
(\%)\end{array}$ & $\begin{array}{l}\text { Kao- } \\
\text { linite } \\
(\%)\end{array}$ & $\begin{array}{c}\text { Chlorite } \\
(\%)\end{array}$ & $\begin{array}{l}\text { Paly- } \\
\text { gorskite } \\
(\%)\end{array}$ & Quartz & Feldspar & $\begin{array}{l}\text { Clinop- } \\
\text { tilolite }\end{array}$ & $\begin{array}{c}\text { X-ray } \\
\text { amorphous } \\
\text { material }\end{array}$ & \\
\hline $576-1-1,46-50$ & $4.96-5.00$ & 43 & 37 & 7 & 13 & & $\mathrm{x}$ & $\mathrm{x}$ & & $\mathrm{x}$ & 48 \\
\hline $576-2-1,109-116$ & $8.29-8.36$ & 52 & 37 & 4 & 7 & & $\mathrm{x}$ & $\mathrm{x}$ & & & 43 \\
\hline $576-2-6,99-106$ & $15.69-15.76$ & 61 & 31 & 4 & 5 & & $\mathrm{x}$ & $\mathrm{x}$ & & $\mathrm{x}$ & 30 \\
\hline $576-3-3,109-115$ & $13.69-13.75$ & 57 & 35 & 3 & 5 & & $\mathrm{x}$ & $x$ & & $\mathrm{x}$ & 33 \\
\hline $576-4-2,88-95$ & $21.48-21.55$ & 52 & 36 & 5 & 7 & & $\mathrm{x}$ & $\mathrm{x}$ & & & 35 \\
\hline $576-4-5,98-104$ & $26.08-26.14$ & 48 & 37 & 6 & 9 & & $\mathrm{x}$ & $\mathrm{x}$ & & & 33 \\
\hline $576-5-1,108-115$ & $29.28-29.35$ & 60 & 30 & 4 & 6 & & $\mathrm{x}$ & $\mathrm{x}$ & & & 38 \\
\hline $576-5-6,18-25$ & $32.78-32.85$ & 61 & 28 & 4 & 6 & & $\mathrm{x}$ & $\mathrm{x}$ & & & 28 \\
\hline $576-6-4,37-44$ & $36.27-36.34$ & 66 & 24 & 4 & 5 & 1 & $\mathrm{x}$ & & & $\mathrm{x}$ & 20 \\
\hline $576-7-2,130-137$ & $46.90-46.97$ & 64 & 28 & 3 & 4 & 2 & $\mathrm{x}$ & & & & 30 \\
\hline $576-7-6,19-26$ & $51.79-51.86$ & 65 & 25 & 4 & 4 & 3 & $\mathrm{x}$ & $\mathrm{x}$ & & $\mathrm{x}$ & 33 \\
\hline $576-8-1,98-105$ & $55.08-55.15$ & 59 & 31 & 3 & 4 & 3 & $\mathrm{x}$ & $\mathrm{x}$ & & $\mathrm{x}$ & 40 \\
\hline $576-8-6,81-84$ & $62.41-62.44$ & 61 & 32 & 2 & 2 & 3 & $\mathrm{x}$ & $\mathrm{x}$ & & $\mathrm{x}$ & 35 \\
\hline $578-2-4,38-45$ & $9.68-9.75$ & 65 & 23 & 4 & 8 & & $\mathrm{x}$ & $\mathrm{x}$ & & $\mathrm{x}$ & 40 \\
\hline $578-5-3,91-98$ & $37.21-37.28$ & 54 & 32 & 5 & 9 & & $\mathrm{x}$ & $\mathrm{x}$ & & $\mathrm{x}$ & 38 \\
\hline $578-10-3,91-98$ & $87.71-87.78$ & 57 & 31 & 4 & 8 & & $\mathrm{x}$ & $\mathrm{x}$ & & & 33 \\
\hline $578-13-1,78-85$ & $110.08-110.15$ & 70 & 24 & 3 & 3 & & $\mathrm{x}$ & $\mathrm{x}$ & & $\mathrm{x}$ & 43 \\
\hline $578-14-4,53-60$ & $123.83-123.90$ & 71 & 22 & 3 & 3 & & $\mathrm{x}$ & $x$ & & & 28 \\
\hline $578-15-2,53-60$ & $130.33-130.40$ & 71 & 24 & 2 & 2 & & $\mathrm{x}$ & $\mathrm{x}$ & & & 18 \\
\hline $578-15-7,28-34$ & $137.58-137.64$ & 72 & 19 & 5 & 4 & & $\mathrm{x}$ & $x$ & & & 23 \\
\hline $578-16-5,67-74$ & $144.47-144.54$ & 65 & 17 & 8 & 10 & & $\mathrm{x}$ & $\mathrm{x}$ & & & 23 \\
\hline $578-17-2,72-79$ & $149.52-149.59$ & 68 & 19 & 7 & 6 & 1 & $\mathrm{x}$ & $x$ & & & 33 \\
\hline $578-17-5,61-68$ & $153.91-153.98$ & 59 & 24 & 7 & 9 & 1 & $\mathrm{x}$ & $\mathrm{x}$ & & $\mathrm{x}$ & 25 \\
\hline $578-18-3,38-45$ & $160.18-160.25$ & 47 & 37 & 5 & 5 & 6 & $\mathrm{x}$ & $\mathrm{x}$ & & & 40 \\
\hline $578-19-1,57-64$ & $166.87-166.94$ & 48 & 34 & 5 & 6 & 6 & $\mathrm{x}$ & $\mathrm{x}$ & & & 40 \\
\hline $578-19-3,53-60$ & $169.83-169.90$ & 62 & 29 & 3 & 3 & 4 & $\mathrm{x}$ & $x$ & & & 38 \\
\hline $581-8-5,65-72$ & $245.15-245.22$ & 77 & 20 & 2 & 1 & & $\mathrm{x}$ & $\mathrm{x}$ & & & 28 \\
\hline $581-9-4,33-40$ & $252.83-252.90$ & 78 & 19 & 2 & 1 & & $\mathrm{x}$ & $\mathrm{x}$ & $\mathrm{x}$ & & 25 \\
\hline $581-10-3,44-51$ & $260.94-261.01$ & 54 & 35 & 0 & 11 & & $\mathrm{x}$ & $\mathrm{x}$ & & & 30 \\
\hline
\end{tabular}

Note: Values obtained using measured peak areas and the factors of Mann and Müller (1979). ML $=$ mixed-layer illite/smectite, $x$ indicates mineral is present, $Z=$ percentage of illite interlayers in illite/smectite.

increased calculated percentages of illite/smectite and correspondingly lower percentages of all other clay minerals present. Similar effects of chemical pretreatment on X-ray intensities have been noted by Brewster (1980). This effect was more dramatic when the Mann and Müller quantification method was used because of the significant enhancement of the low $2 \theta(001)$ peak for illite/ smectite. Values of percent illite/smectite were increased by 15 to $20 \%$ for the Mann and Müller method and by 0 to $10 \%$ for the Hoffman method when amorphous Feoxyhydroxides were removed. Although all methods are admittedly semiquantitative, the significant influence of chemical pretreatments on the results makes interpretation of clay data even more difficult. It is interesting to note, however, that the removal of amorphous Fe-oxyhydroxides did not affect the interpretation of the amount of illite layers in the mixed-layer illite/smectite phase. Comparison of the various results presented here illustrates the need for standardized procedures in quantification of clay mineralogy, especially for mixed-layer clay minerals, from X-ray diffraction data.

There is a very general trend of increasing percent illite/smectite with depth in Hole 576 (Fig. 5). Two regions of particularly high mixed-layer clay mineral content (about $16 \mathrm{~m}$ and $36-52 \mathrm{~m}$ sub-bottom) are superimposed on this general trend. Furthermore, samples of high mixed-layer content tend to have illite/smectite with fewer illite interlayers.

Discrete illite content declines with depth in Hole 576 and mirrors the pattern of mixed-layer content. Kaolinite and chlorite percentages both decrease with depth in Hole 576 (Fig. 5). Palygorskite was first detected in $\mathrm{X}$-ray diffractograms of samples from a depth of about $36 \mathrm{~m}$ sub-bottom, and increases in concentration were detected to the base of Hole 576 .

The percentage of mixed-layer illite/smectite appears to oscillate somewhat with depth at Site 578 , with a pronounced zone of maximum percent mixed-layer clay from about 110 to $145 \mathrm{~m}$ sub-bottom. The composition of the mixed-layer clay mineral (given as \% illite interlayers, Fig. 6) again tends to reflect the quantity of illite/smectite, as in Hole 576. In general, mixed-layer, clay-mineral-rich sediment samples have fewer illite interlayers in the illite/smectite. As was also the case for Hole 576, the depth trend of discrete illite mirrors that of mixedlayer illite/smectite (Fig. 6). Kaolinite and chlorite percentages decrease slightly with depth down to about $130 \mathrm{~m}$ sub-bottom. Below this depth the concentrations of both minerals increase sharply to roughly $8 \%$ kaolinite and $10 \%$ chlorite and then decline again to the bottom of the hole. Palygorskite first appears in X-ray patterns of sediments at a depth of about $150 \mathrm{~m}$ and increases in percentage downhole (Fig. 6).

The relative percentages of mixed-layer illite/smectite, illite, kaolinite, and chlorite at Site 581 are similar to those found in samples from Holes 576 and 578 (cf. Figs. 5, 6, and 7). The shift from high mixed-layer and low illite content to the reverse with depth in Hole 581 is similar to the depth profile of Hole 578 between 140 and $150 \mathrm{~m}$. The high chlorite content of the sample from Section 581-10-3 (the deepest sample from Hole 581) is also consistent with the depth variations in Hole 578, al- 

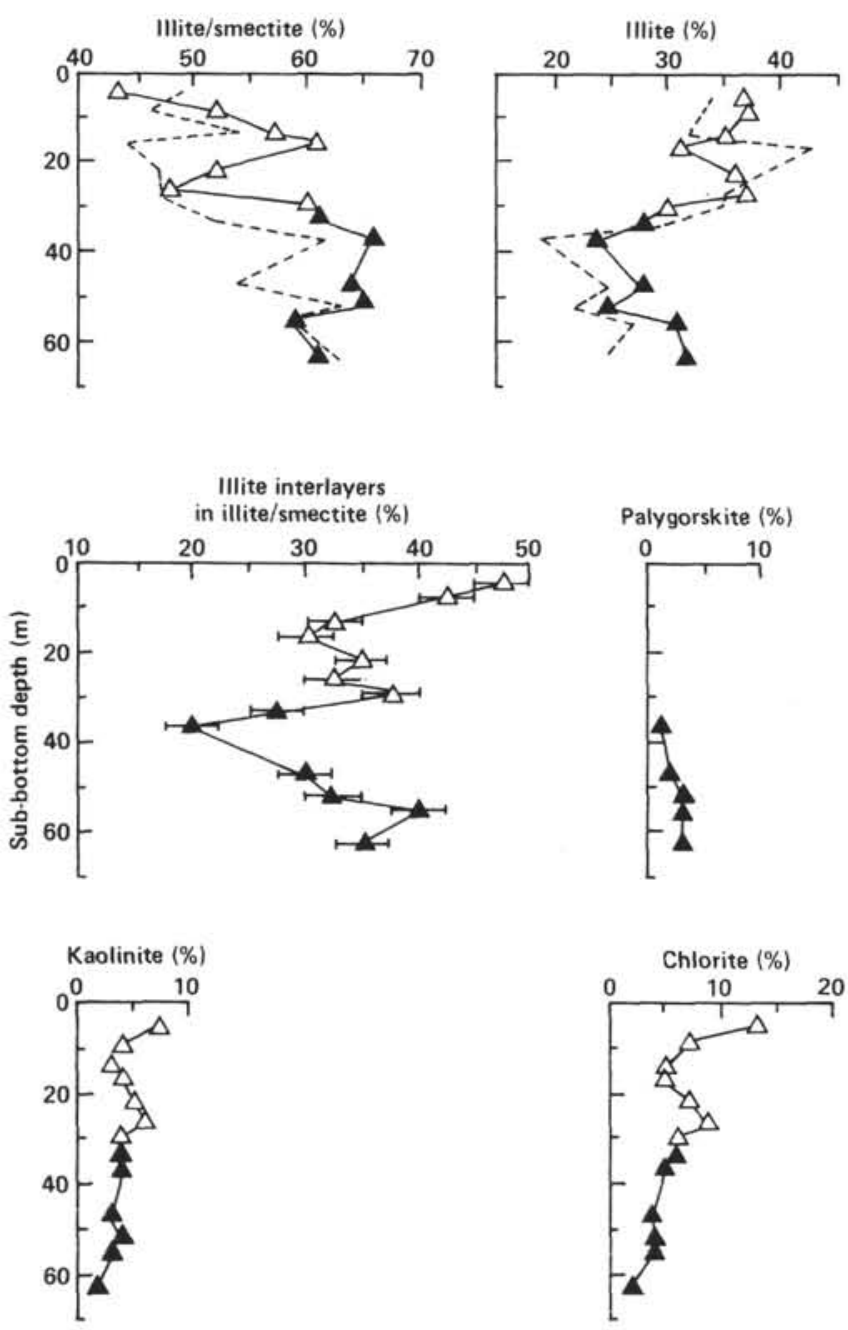

Figure 5. Clay mineralogy of the $<2-\mu \mathrm{m}$ size fraction of samples from Hole 576. Symbols as in Figure 3. Significance of solid and dashed lines is discussed in text.

though the disappearance of kaolinite in Hole 581 is different. No palygorskite was detected in X-ray diffraction patterns of samples from Hole 581 .

\section{Chemistry}

Analyses of major and trace-element concentrations were made for selected samples; these data are given in Table 3. In general, the chemical compositions of all pelagic clays from the three sites studied are similar, although significant depth trends are evident for nearly all elements in Holes 576 and 578. The chemistry of the two samples from Hole 581 is similar to that of samples from below about $130 \mathrm{~m}$ sub-bottom in Hole 578 .

The depth profiles of weight percent $\mathrm{Al}_{2} \mathrm{O}_{3}$ and $\mathrm{SiO}_{2}$ for Holes 576 and 578 are shown in Figure 8. The percent $\mathrm{SiO}_{2}$ after subtraction of the $\mathrm{SiO}_{2}$ in quartz as determined by X-ray diffraction represents $\mathrm{SiO}_{2}$ in other silicate minerals. No attempt was made to quantify the percent $\mathrm{SiO}_{2}$ in opaline silica, although it appears to be a minor component in all but a few samples.

In Hole $576, \mathrm{Al}_{2} \mathrm{O}_{3}$ decreases slightly downhole from about 16.5 to $14 \%$, with a maximum of over $17 \%$ in the intermediate depth range of $20-30 \mathrm{~m}$ sub-bottom. Total
$\mathrm{SiO}_{2}$ decreases downhole from about 58 to $48 \%$ in Hole 576 , although non-quartz $\mathrm{SiO}_{2}$ initially increases, then decreases slightly, with depth. The depth trends of decreasing percent $\mathrm{Al}_{2} \mathrm{O}_{3}$ and increasing percent non-quartz $\mathrm{SiO}_{2}$ are consistent with the trends in clay mineralogy noted earlier (Fig. 5). Smectite has a higher $\mathrm{Si} / \mathrm{Al}$ ratio than illite, and the general increase in percent illite/smectite and decline of percent illite with depth in Hole 576 are reflected in the changes in percent $\mathrm{Al}_{2} \mathrm{O}_{3}$ and percent non-quartz $\mathrm{SiO}_{2}$.

In Hole $578, \mathrm{Al}_{2} \mathrm{O}_{3}$ increases slightly with depth to a maximum of $17.5 \%$ at about $138 \mathrm{~m}$ sub-bottom, then decreases to the bottom of the hole (Fig. 8). $\mathrm{SiO}_{2}$ decreases downhole from about 60 to $40 \%$, then increases near the base of the hole. Corrected for quartz, the $\mathrm{SiO}_{2}$ profile appears fairly uniform with depth, perhaps decreasing slightly downhole (Fig. 8). The presence of small amounts of volcanic glass and siliceous microfossils in the upper $120 \mathrm{~m}$ of Hole 578 , as noted in smear slides (see Site 578 chapter, this volume), would result in higher $\mathrm{SiO}_{2}$ and lower $\mathrm{Al}_{2} \mathrm{O}_{3}$ percentages. If a correction to the percent $\mathrm{SiO}_{2}$ profile were made to account for these components, the depth trends would probably be more similar to those from Hole 576. Without corrections for volcanic glass and siliceous microfossils, it is difficult to relate the $\mathrm{SiO}_{2}$ and $\mathrm{Al}_{2} \mathrm{O}_{3}$ contents to clay mineralogy, although the zone of high illite/smectite content between 110 and $150 \mathrm{~m}$ sub-bottom (Fig. 6) is also a region of relatively high percent non-quartz $\mathrm{SiO}_{2}$ (Fig. 8).

The depth trends of other major elements are similar in Holes 576 and 578 (Table 3). Percentages of $\mathrm{Fe}_{2} \mathrm{O}_{3}$, $\mathrm{K}_{2} \mathrm{O}, \mathrm{MgO}$, and $\mathrm{MnO}$ increase with depth at both sites. Several trace elements $(\mathrm{Cu}, \mathrm{Co}$, and $\mathrm{Ni}$ in both holes; $\mathrm{Sr}, \mathrm{Pb}$, and $\mathrm{Zr}$ in Hole 578 only) covary with $\mathrm{MnO} . \mathrm{Cr}$ shows an antithetical relationship with $\mathrm{MnO}$ in Hole 578. The high percentages of $\mathrm{Fe}_{2} \mathrm{O}_{3}, \mathrm{MnO}$, and associated trace elements probably reflect authigenic $\mathrm{Fe}$ and $\mathrm{Mn}$ oxyhydroxides. The increase of percent $\mathrm{K}_{2} \mathrm{O}$ with depth is related to the changing abundance of illite. Illite is present both as a discrete phase and as illite interlayers in the mixed-layer illite/smectite. Percentage $\mathrm{K}_{2} \mathrm{O}$ reflects the summation of percent discrete and interlayered illite (Fig. 9). The percentage of $\mathrm{CaO}$ initially decreases slightly with depth and then increases downhole in both holes. $\mathrm{P}_{2} \mathrm{O}_{5}$ in Hole 576 and $\mathrm{Sr}$ in Hole 578 tend to covary with $\mathrm{CaO}$. The trends of percentage $\mathrm{CaO}$ are probably due to variable contents of biogenic calcite, and perhaps trace amounts of phillipsite in some samples, and to decreasing plagioclase feldspar contents with depth. $\mathrm{Na}_{2} \mathrm{O}$ decreases in percentage downhole in both holes, reflecting the decline of feldspar content with depth.

The downhole variations of chemistry at all three sites are possibly most clearly demonstrated by the increase in metals associated with authigenic oxyhydroxides (Fe, $\mathrm{Mn}, \mathrm{Cu}, \mathrm{Co}$, and $\mathrm{Ni}$ ) and the decreases in $\mathrm{Si}$. The trends with depth of these two parameters are indicated in Figure 10 by arrows pointing in the downhole direction for each site.

\section{Physical Properties}

Emphasis in this study was on the clay mineral-rich sediment of Sites 576, 578, and 581 and on evaluation 

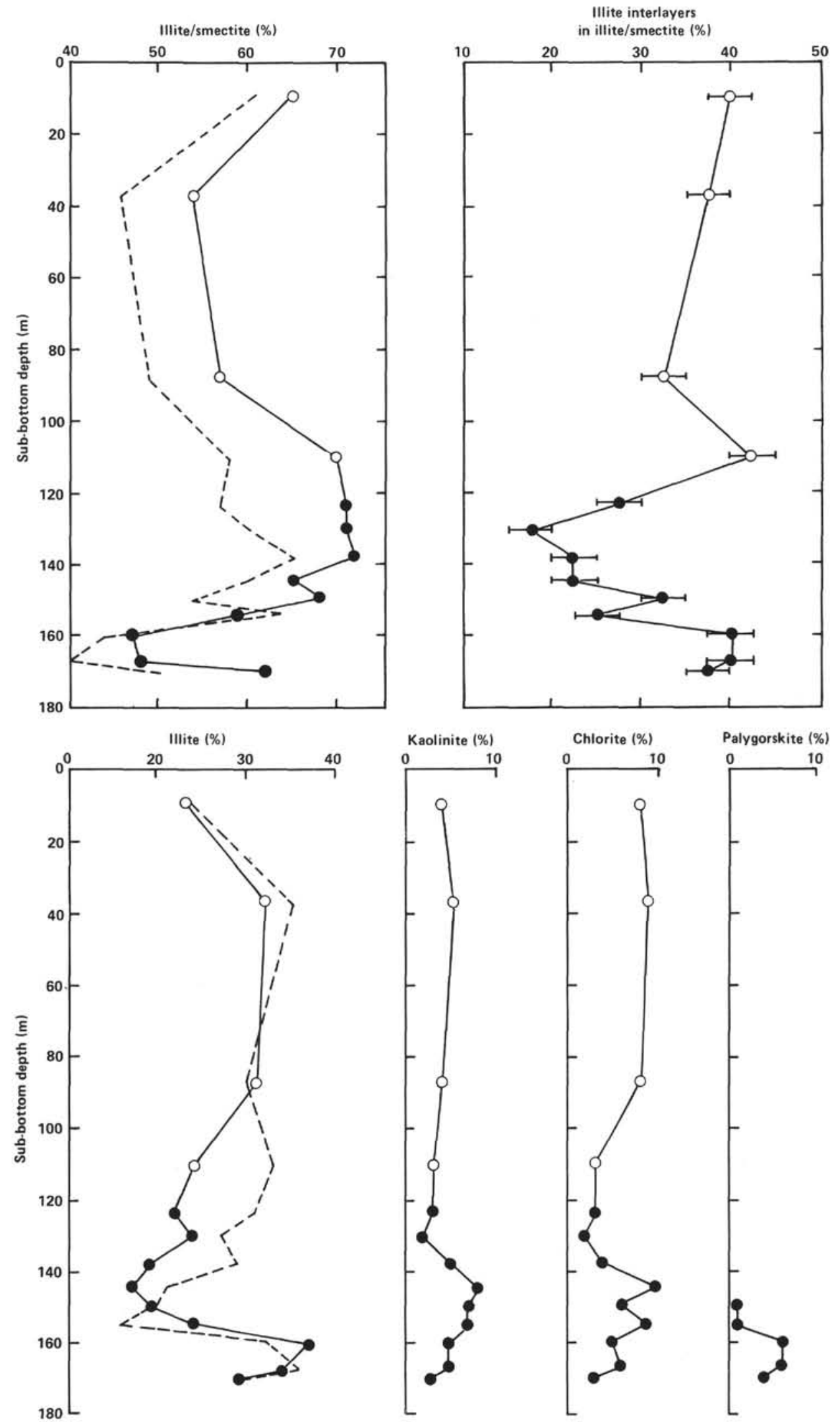

Figure 6. Clay mineralogy of the $<2-\mu \mathrm{m}$ size fraction of samples from Hole 578 . Symbols as in Figure 3. Significance of solid and dashed lines is discussed in text. 


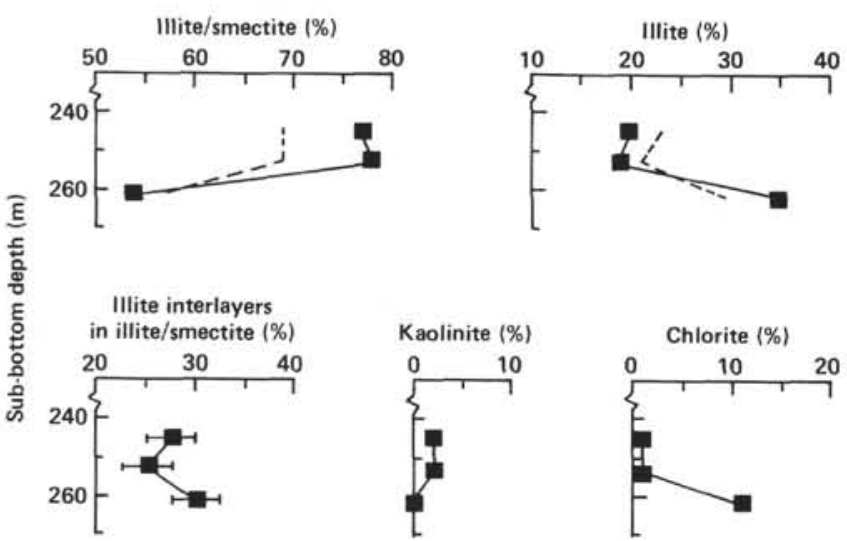

Figure 7. Clay mineralogy of the $<2-\mu \mathrm{m}$ size fraction of samples from Hole 581. Symbols as in Figure 3. Significance of solid and dashed lines is discussed in text. of vertical gradients in physical properties as a function of compaction of the pelagic clay sequences. Consequently, most of the data in this section are portrayed as a function of burial depth of the sediments. Futhermore, we will be concerned mainly with a unit of relatively homogeneous brown pelagic clay which is described in detail in the discussion section.

\section{Bulk Density}

Laboratory-determined saturated bulk densities of the clay samples are given in Table 4 and shown as a function of sub-bottom depth (equivalent to burial depth) in Figure 11. In general, bulk density increases with burial depth in all three holes. This density increase reflects a decrease in porosity, and thus water content, of the pelagic clay sediments with increasing burial depth (Schultheiss, this volume). The density variation of brown pelagic clay from Hole 576 to 578 to 581 is of particular interest. There appears to be within each hole, and be-

Table 3. Concentrations of major and trace elements in selected bulk samples from Holes 576, 578, and 581.

\begin{tabular}{|c|c|c|c|c|c|c|c|c|c|c|c|c|c|c|c|c|c|c|c|c|c|c|c|c|c|c|}
\hline \multirow{2}{*}{$\begin{array}{c}\text { Sample } \\
\text { (interval in } \mathrm{cm} \text { ) }\end{array}$} & \multirow{2}{*}{$\begin{array}{l}\text { Sub-bottom } \\
\text { depth } \\
\text { (m) }\end{array}$} & \multicolumn{10}{|c|}{ Major elements (\%) } & \multicolumn{15}{|c|}{ Trace elements (ppm) } \\
\hline & & $\mathrm{Al}_{2} \mathrm{O}_{3}$ & $\mathrm{Fe}_{2} \mathrm{O}_{3}$ & $\mathrm{CaO}$ & $\mathrm{MgO}$ & $\mathrm{TiO}_{2}$ & $\mathrm{MnO}$ & $\mathrm{Na}_{2} \mathrm{O}$ & $\mathrm{K}_{2} \mathrm{O}$ & $\mathrm{P}_{2} \mathrm{O}_{5}$ & $\mathrm{SiO}_{2}$ & Be & $\mathrm{Cr}$ & Co & $\mathrm{Cu}$ & $\mathbf{P b}$ & $\mathrm{Ni}$ & Ba & Sr & Th & $\mathrm{Zr}$ & $\mathrm{v}$ & $\mathrm{Zn}$ & $\mathrm{Cd}$ & Mo & $A_{8}$ \\
\hline $576-1-1,46-50$ & $4.96-5.00$ & 16.4 & 7.45 & 0.96 & 2.93 & 0.743 & 0.445 & 1.78 & $\mathbf{3 . 3 0}$ & 0.11 & 57.2 & 2.2 & 56.4 & 42 & 143 & 35 & 66 & 619 & 140 & 35 & 113 & 134 & 113 & $<7$ & $<30$ & $<5$ \\
\hline $576-2-6,99-106$ & $15.69-15.76$ & 16.1 & 7.08 & 0.80 & 3.12 & 0.729 & 0.703 & 1.50 & 3.16 & 0.10 & 58.3 & 2.3 & 70.0 & 59 & 205 & 80 & 98 & 735 & 126 & 21 & 109 & 129 & 117 & $<7$ & $<30$ & $<5$ \\
\hline $576-4-2,88-95$ & $21.48-21.55$ & 17.1 & 7.77 & 0.78 & 3.14 & 0.768 & 0.943 & 1.53 & 3.46 & 0.10 & 53.4 & 2.5 & 70.9 & 84 & 246 & 40 & 121 & 594 & 130 & 26 & 133 & 145 & 134 & $<7$ & $<30$ & $<5$ \\
\hline $576-5-1,108-115$ & $29.28-29.35$ & 17.3 & 8.23 & 0.76 & 3.27 & 0.806 & 1.35 & 1.42 & 3.51 & 0.16 & 54.0 & 2.4 & 55.8 & 148 & 280 & so & 192 & 525 & 137 & 34 & 160 & 143 & 168 & $<7$ & $<30$ & $<5$ \\
\hline $576-5-6,18-25$ & $32.78-32.85$ & 16.2 & 8.21 & 1.12 & 3.04 & 0.791 & 2.48 & 1.59 & 3.40 & 0.37 & 50.5 & 2.2 & 39.0 & 297 & 418 & 55 & 388 & 438 & 173 & 41 & 180 & 135 & 178 & $<7$ & $<30$ & $<5$ \\
\hline $576-7-6,19-26$ & $51.79-51.86$ & 15,3 & 8.19 & 2.31 & 3.29 & 0.721 & 1.89 & 0.868 & 4.05 & 1.35 & 49.4 & 2.1 & 31.6 & 164 & 226 & so & 242 & 481 & 173 & 38 & 180 & 132 & 184 & $<7$ & $<30$ & $<5$ \\
\hline $576-8-1,98-105$ & $55.08-55.15$ & 14.0 & 8.61 & 2.27 & 3.33 & 0.751 & 3.41 & 0.875 & 4.36 & 1.25 & 47.7 & 2,4 & 29.7 & 298 & 300 & 75 & 463 & 611 & 241 & 53 & 219 & 168 & 249 & $<7$ & $<30$ & 6 \\
\hline $578 \cdot 2-4,38-45$ & $9.68-9.75$ & 14,3 & 6.60 & 1.49 & 2.57 & 0.656 & 0.104 & 1.91 & 2.71 & 0.08 & 59.7 & 1.7 & 66.6 & $<3$ & 75.8 & is & 41 & 741 & 137 & $<6$ & 83 & 122 & 96 & $<7$ & $<30$ & $<5$ \\
\hline $578 \cdot 5-3,91-98$ & $37.21-37.28$ & 14.8 & 6.76 & 1.31 & 2.52 & 0.641 & 0.0994 & 1.80 & 2.61 & 0.08 & 61.0 & 1.7 & 61.2 & $<3$ & 76.8 & 20 & 45 & 606 & 124 & $<6$ & 84 & 102 & 98 & $<7$ & $<30$ & $<s$ \\
\hline $578-10-3,91-98$ & $87.71-87.78$ & 15.3 & 6.73 & 1.49 & 2.42 & 0.652 & 1.19 & 2.12 & 2,78 & 0.10 & 58.3 & 1.9 & 48.7 & 12 & 174 & 40 & 62 & 607 & 130 & $<6$ & 98 & 125 & 136 & $<7$ & $<30$ & $<5$ \\
\hline $578-13-1,78-85$ & $110.08-110.15$ & 15.3 & 6.41 & 0.84 & 2.35 & 0.635 & 0.362 & 1.79 & 3.23 & 0.09 & 60.1 & 2.2 & 71.7 & $<3$ & iss & 30 & 62 & 606 & 109 & 6 & 112 & 121 & 117 & $<7$ & $<30$ & $<5$ \\
\hline $578-14-4,53-60$ & $123.83-123.90$ & 17.0 & 7.08 & 0.73 & 3.06 & 0.695 & 0.663 & 1.48 & 2.86 & 0.09 & 55.0 & 2.2 & 65.7 & 10 & 168 & 30 & 81 & 551 & 104 & 6 & 114 & III & 126 & $<7$ & $<30$ & $<5$ \\
\hline $578-15-7,28-34$ & $137.58-137.64$ & 17.5 & 7.51 & 0.50 & 2.95 & 0.743 & 1.01 & 1.26 & 3.10 & 0.11 & 53.3 & 2.4 & 55.5 & 53 & 238 & 35 & 112 & 606 & 116 & $<6$ & 126 & 148 & 121 & $<?$ & $<30$ & $<5$ \\
\hline $578-17-5,61-68$ & $153.91-153.98$ & 15.9 & 8.65 & 1.35 & 2.98 & 0.749 & 3.69 & 0.926 & 3.08 & 0.62 & 46,6 & 2.0 & 30.6 & 356 & 309 & 70 & 469 & 426 & 262 & $<6$ & 197 & 142 & 217 & $<7$ & $<30$ & $<5$ \\
\hline $578-18-3,38-45$ & $160.18-160.25$ & 16.4 & 7.38 & 0.70 & 3.66 & 0.703 & 1.20 & 0.750 & 3.91 & 0.33 & 53.6 & 2.2 & 67.3 & 36 & 134 & 45 & 207 & 378 & 132 & $<6$ & 137 & 119 & 133 & $<7$ & $<30$ & $<3$ \\
\hline $578-19-3,53-60$ & $169.83-169.90$ & 15.4 & 7.48 & 1.93 & 3.14 & 0.691 & 1.53 & 0.896 & 3.99 & 1.05 & 52.1 & 2.0 & 40.6 & 125 & 218 & 50 & 264 & 524 & 190 & 10 & 179 & 129 & 172 & $<7$ & $<30$ & $<5$ \\
\hline $581-8.5 .65-72$ & $245.15-245.22$ & 15.0 & 6.84 & 0.52 & 3.02 & 0.262 & 0.782 & 1.12 & 2.82 & 0.06 & 57.3 & 3.1 & 44.5 & 63 & 252 & 30 & 141 & 1700 & 106 & 32 & 59 & 108 & 140 & $<7$ & $<30$ & $<5$ \\
\hline $581-10-3,44-51$ & $260.94-261.01$ & 17.5 & 6.98 & 0.60 & 3.28 & 0.629 & 2.44 & 1.25 & 3.67 & 0.23 & 51.5 & 2.7 & 37.7 & 243 & 331 & so & 364 & 736 & 214 & $5 i$ & 170 & 133 & 174 & $<7$ & $<30$ & $<5$ \\
\hline
\end{tabular}

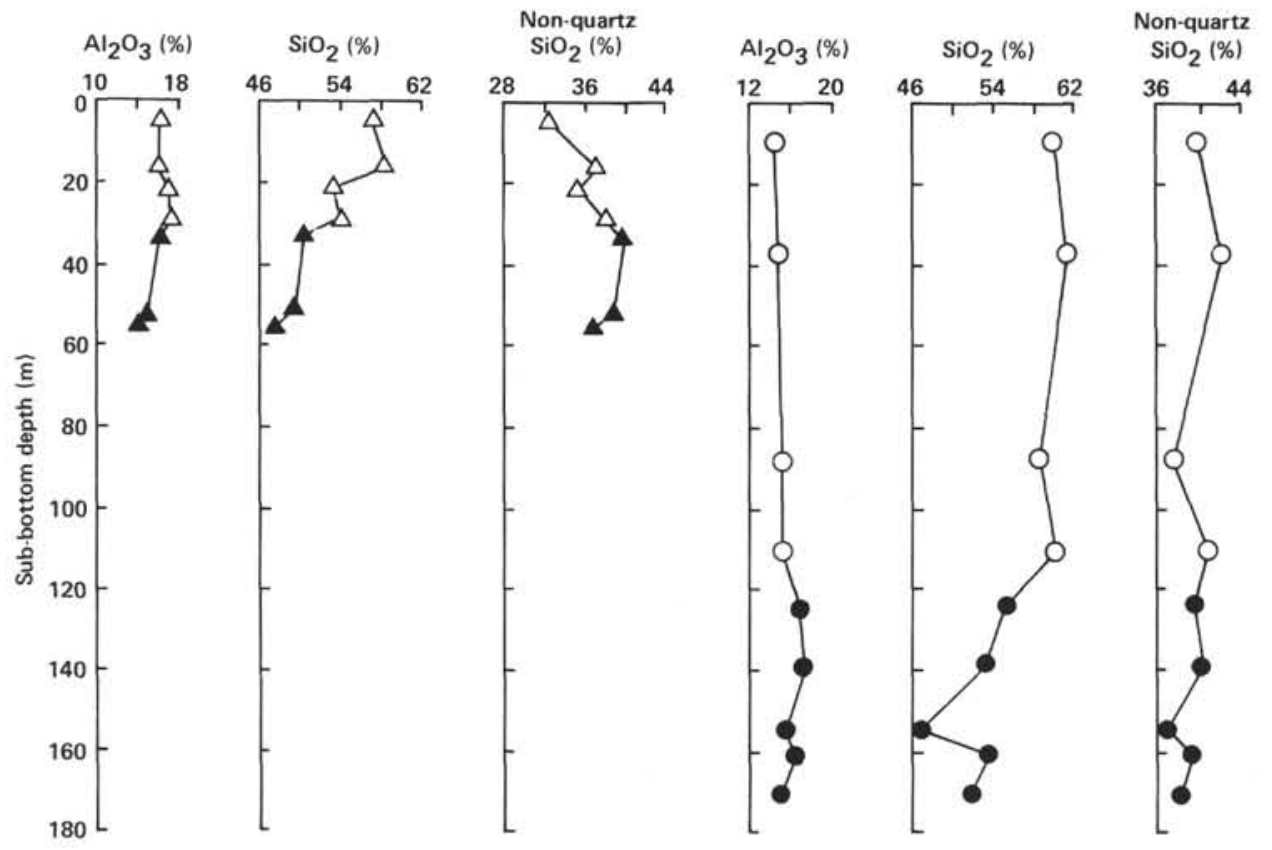

Figure 8. Percentage $\mathrm{Al}_{2} \mathrm{O}_{3}, \mathrm{SiO}_{2}$, and non-quartz $\mathrm{SiO}_{2}$ of samples from Holes 576 and 578. Symbols as in Figure 3. 


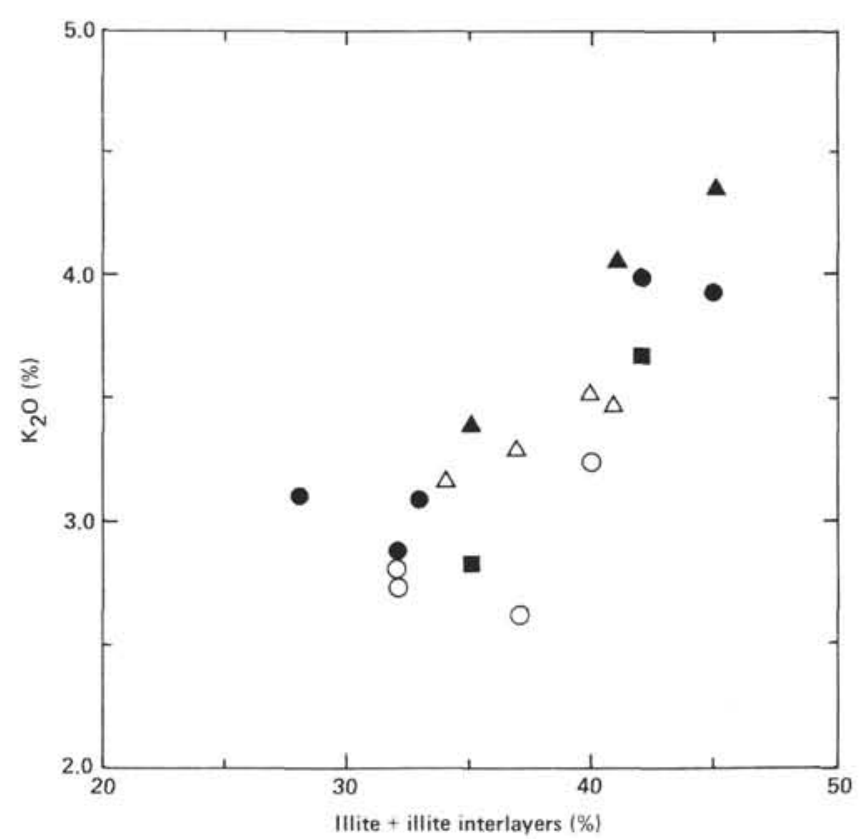

Figure 9. Percentage $\mathrm{K}_{2} \mathrm{O}$ plotted versus the sum of percentage discrete illite and percentage illite interlayers in illite/smectite mixedlayer clay for bulk samples of clay-rich sediments from Leg 86. Symbols as in Figure 3.

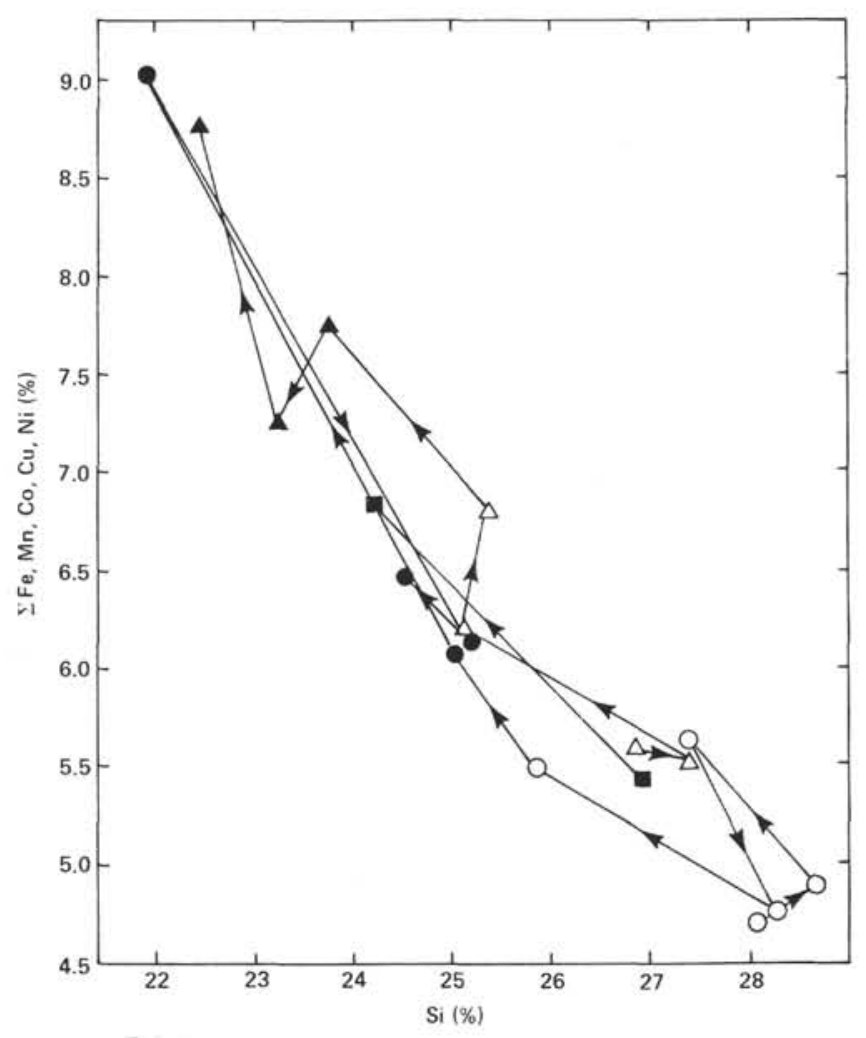

Figure 10. Summation of the metals $\mathrm{Fe}, \mathrm{Mn}, \mathrm{Co}, \mathrm{Cu}$, and Ni plotted versus percentage $\mathrm{Si}$ for the clay samples of Holes 576, 578, and 581. Lines with arrows connect data points for each hole; arrows point in a downhole direction, indicating the general increase in metal content and decrease in percentage $\mathrm{Si}$ downhole at all three sites. Symbols as in Figure 3. tween holes, a general increase, perhaps non-linear, in density in this unit with increasing burial depth (Fig. 11). In Hole 581, however, the saturated bulk density of the brown pelagic clay at $245-255 \mathrm{~m}$ sub-bottom is nearly the same as that from 130-155 m sub-bottom in Hole 578. Also, the water content in the brown pelagic clay in Hole 581 at $262 \mathrm{~m}$ is $75 \%$, whereas at Sites 576 and 578 water contents $20 \%$ less than this value are found at depths of 60 and $170 \mathrm{~m}$ sub-bottom, respectively (Schultheiss, this volume). Possible reasons for this apparently anomalous situation in density will be discussed later.

\section{Electrical Resistivity}

The major purpose of this section is to present the resistivity data obtained for the pelagic clays from Sites 576,578 , and 581 . It is worthwhile initially, however, to consider some concepts concerning the relationship between electrical conductivity and sediment characteristics. Details are given in a number of publications summarized for DSDP studies by Boyce $(1980,1981)$.

Electricity will pass through marine sediments because an electrolyte-rich water is present in the pores and absorbed on clay particles; dry sediment generally is a poor conductor of electricity. Conduction of electricity in a saturated sediment is complicated because of the presence of a granular framework. If the framework minerals are nonconductive, then the passage of electricity is through the interstitial water. In pelagic clay, where clay minerals exchange ions with the interstitial water, it would be anticipated that the conduction of electricity would be more complicated. Clay minerals with differing ion-exchange capacities may act as conductors or resistors of electricity relative to different pore-water resistivities.

The electrical resistivity of any material is the resistance in ohms between opposite faces of a unit cube of the material and is defined as

$$
R_{\mathrm{o}}=r A / L\left(\text { ohm } \mathrm{m}^{2} \mathrm{~m}^{-1}\right. \text { or ohm-m), }
$$

where $R_{\mathrm{o}}$ is the resistivity, and $r$ is the resistance of a conducting cube with cross-sectional area $A$ and length $L$. To a first approximation, it is likely that in the shallowly buried clay sediments of Sites 576, 578, and 581, the in situ resistivity of the interstitial water is nearly constant with burial depth. Neither pore-water salinities nor sediment temperatures change significantly with burial depth (see Site 576, 578, and 581 chapters, this volume). Laboratory sediment resistivities were measured at a constant temperature of $23^{\circ} \mathrm{C}$. Thus, the laboratory determinations of resistivity of the sediments from these sites will depend primarily on the amount of water present (i.e., the porosity) and on the fabric of the sediment (i.e., the size, shape, and arrangement of detrital grains and authigenic minerals).

For a homogeneous sediment completely saturated with seawater, its resistivity, $R_{\mathrm{o}}$, is proportional to the resistivity of the seawater, $R_{\mathrm{sw}}$, at the same temperature and pressure,

$$
R_{\mathrm{o}}=F R_{\mathrm{sw}}
$$


Table 4. Measured bulk densities and compressional-wave velocities for samples from Holes 576, 578 , and 581 .

\begin{tabular}{|c|c|c|c|c|c|c|c|}
\hline \multirow[b]{2}{*}{$\begin{array}{l}\text { Sample } \\
\text { (interval in } \mathrm{cm} \text { ) }\end{array}$} & \multirow{2}{*}{$\begin{array}{l}\text { Sub-bottom } \\
\text { depth } \\
\text { (m) }\end{array}$} & \multirow{2}{*}{$\begin{array}{c}\text { Bulk } \\
\text { density } \\
\left(\mathrm{g} / \mathrm{cm}^{3}\right)\end{array}$} & \multicolumn{4}{|c|}{ Compressional velocity $V_{\mathrm{p}}(\mathrm{km} / \mathrm{sec})$} & \multirow[b]{2}{*}{$\begin{array}{c}\text { Anisotropy } \\
A_{\mathrm{p}}(\%)\end{array}$} \\
\hline & & & $\begin{array}{c}\text { Vertical } \\
V_{\text {pv }}\end{array}$ & $\begin{array}{c}\text { Horizontal } \\
V_{\mathrm{ph}} \mathrm{A}\end{array}$ & $\begin{array}{c}\text { Horizontal } \\
V_{\mathrm{ph}} \mathrm{B}\end{array}$ & $\begin{array}{c}\bar{X} \\
V_{\mathrm{ph}}\end{array}$ & \\
\hline $576-1-1,46-50$ & $4.96-5.00$ & 1.474 & 1.527 & 1.566 & 1.543 & 1.554 & +1.75 \\
\hline $576-2-1,109-116$ & $8.29-8.36$ & 1.455 & 1.533 & 1.510 & 1.506 & 1.508 & -1.65 \\
\hline $576-2-6,99-106$ & $15.69-15.76$ & 1.362 & 1.531 & 1.581 & 1.524 & 1.553 & +1.42 \\
\hline $576-3-3,109-115$ & $13.69-13.75$ & 1.375 & 1.485 & 1.507 & 1.497 & 1.502 & +1.14 \\
\hline $576-4-2,88-95$ & $21.48-21.55$ & 1.378 & 1.460 & 1.526 & 1.513 & 1.520 & +4.00 \\
\hline $576-4-5,98-104$ & $26.08-26.14$ & 1.403 & 1.492 & 1.488 & 1.507 & 1.498 & +0.40 \\
\hline $576-5-1,108-115$ & $29.28-29.35$ & 1.398 & 1.496 & 1.489 & 1.495 & 1.492 & -0.27 \\
\hline $576-5-6,18-25$ & $32.78-32.85$ & 1.363 & 1.502 & 1.509 & 1.521 & 1.515 & +0.86 \\
\hline $576-6-4,37-44$ & $36.27-36.34$ & 1.421 & 1.503 & 1.507 & 1.495 & 1.501 & -0.13 \\
\hline $576-7-2,130-137$ & $46.90-46.97$ & 1.397 & 1.477 & 1.488 & 1.498 & 1.493 & +1.08 \\
\hline $576-7-6,19-26$ & $51.79-51.86$ & 1.462 & 1.497 & 1.504 & 1.510 & 1.507 & +0.67 \\
\hline $576-8-1,98-105$ & $55.08-55.15$ & 1.411 & 1.508 & 1.502 & 1.508 & 1.505 & -0.20 \\
\hline $576-8-6,81-84$ & $62.41-62.44$ & 1.398 & 1.513 & 1.501 & 1.545 & 1.523 & +0.66 \\
\hline $578-2-4,38-45$ & $9.68-9.75$ & 1.319 & 1.613 & 1.562 & 1.532 & 1.547 & -4.21 \\
\hline $578-5-3,91-98$ & $37.21-37.28$ & 1.346 & 1.513 & 1.519 & 1.526 & 1.523 & +0.66 \\
\hline $578-10-3,91-98$ & $87.71-87.78$ & 1.351 & 1.532 & 1.535 & 1.541 & 1.538 & +0.39 \\
\hline $578-13-1,78-85$ & $110.08-110.15$ & 1.364 & 1.534 & 1.520 & 1.514 & 1.517 & -1.12 \\
\hline $578-14-4,53-60$ & $123.83-123.90$ & 1.407 & 1.521 & 1.530 & 1.532 & 1.531 & +0.65 \\
\hline $578-15-2,53-60$ & $130.33-130.40$ & 1.464 & 1.524 & 1.536 & 1.549 & 1.543 & +1.24 \\
\hline $578-15-7,28-34$ & $137.58-137.64$ & 1.467 & 1.509 & 1.530 & 1.545 & 1.538 & +1.90 \\
\hline $578-16-5,67-74$ & $144.47-144.54$ & 1.497 & 1.535 & 1.538 & 1.542 & 1.540 & +0.33 \\
\hline $578-17-2,72-79$ & $149.52-149.59$ & 1.508 & 1.513 & 1.510 & 1.536 & 1.523 & +0.66 \\
\hline $578-17-5,61-68$ & $153.91-153.98$ & 1.453 & 1.512 & 1.524 & 1.530 & 1.527 & +0.99 \\
\hline $578-18-3,38-45$ & $160.18-160.26$ & 1.620 & 1.520 & 1.552 & 1.567 & 1.560 & +2.59 \\
\hline $578-19-1,57-64$ & $166.87-166.94$ & 1.575 & 1.516 & 1.530 & 1.544 & 1.537 & +1.37 \\
\hline $578-19-3,53-60$ & $169.83-169.90$ & 1.603 & 1.526 & 1.568 & 1.566 & 1.567 & +2.64 \\
\hline $581-8-5,65-72$ & $245.15-245.22$ & 1.471 & 1.519 & 1.541 & 1.538 & 1.540 & +1.37 \\
\hline $581-9-4,33-40$ & $252.83-252.90$ & 1.517 & 1.526 & 1.541 & 1.559 & 1.550 & +1.56 \\
\hline $581-10-3,44-51$ & $260.94-261.01$ & 1.543 & 1.541 & 1.542 & 1.553 & 1.548 & +0.45 \\
\hline
\end{tabular}

$F$ is commonly called the formation factor (Archie, 1942, 1950). The formation factor is a parameter that accounts for the tortuous path electricity follows through a sediment of varying grain size and shape, mineral arrangement, and porosity. Thousands of laboratory determinations on thousands of samples (mainly sandstones and carbonates) (Schlumberger, 1958) have shown that an empirical relationship for $F$ and porosity is

$$
F=a \Phi^{-m},
$$

where $\Phi$ is porosity, and $a$ and $m$ are constants.

It is possible that the passage of electricity through freshly deposited marine sediment is isotropic. In pelagic clays, however, where clay minerals of flat or elongated shape are deposited and during compaction are preferentially oriented with their least size dimension perpendicular to bedding, bedding planes will offer a favorable path for the conduction of electricity. Thus, resistivity parallel to bedding is typically less than that perpendicular to bedding in clay mineral-bearing sediments. Resistivity anisotropy with horizontal resistivity less than vertical resistivity should develop in these sediments with increasing burial depth. Resistivity anisotropy is defined as

$$
A_{\mathrm{r}}=100\left(R_{\mathrm{v}}-R_{\mathrm{h}}\right) / R
$$

where $R_{\mathrm{v}}$ is vertical resistivity, $R_{\mathrm{h}}$ is horizontal resistivity, and $\frac{v}{R}$ is mean sample resistivity. In later sections, following presentation of the physical property data, we will employ some of these concepts in interpretation of the resistivity data.

Figures 12 and 13 show vertical gradients in laboratory-determined horizontal and vertical resistivities and resistivity anisotropy, respectively. Table 5 gives the data for these parameters. Emphasis in resistivity measurements was placed on the brown pelagic clay samples. In general, the resistivity of the brown pelagic clay increases irregularly with increasing burial depth. Vertical $\left(R_{\mathrm{v}}\right)$ resistivities tend to be greater than horizontal $\left(R_{\mathrm{h}}\right)$ and resistivity anisotropy $\left(A_{\mathrm{r}}\right)$ appears to increase with increasing burial depth. Site 581 brown pelagic clay appears anomalous once more, based on very limited data; resistivities and resistivity anisotropies seem less than anticipated for the depth of burial of the clay sequence at this site.

It is difficult to determine whether some of the scatter, specifically the large single point deviations in resistivity and resistivity anisotropy, is a result of disturbances in core samples (e.g., deformation during coring or subsequent dessication), errors in laboratory measurement, or real changes in sediment properties. If we include all the measurements, the sediments exhibit resistivity values ranging from about 0.5 to slightly greater than $1.3 \mathrm{ohm}$ and resistivity anisotropies of about -15 to $+47 \%$. Below a depth of about $30 \mathrm{~m}$, the resistivity anisotropy is positive, whereas above that depth some pelagic clay samples show negative anisotropy values. Most samples of the brown pelagic clay exhibited positive resistivity anisotropy $\left(R_{\mathrm{y}}>R_{\mathrm{h}}\right)$, with values ranging from about 2 to $47 \%$. It is possible that some of the 


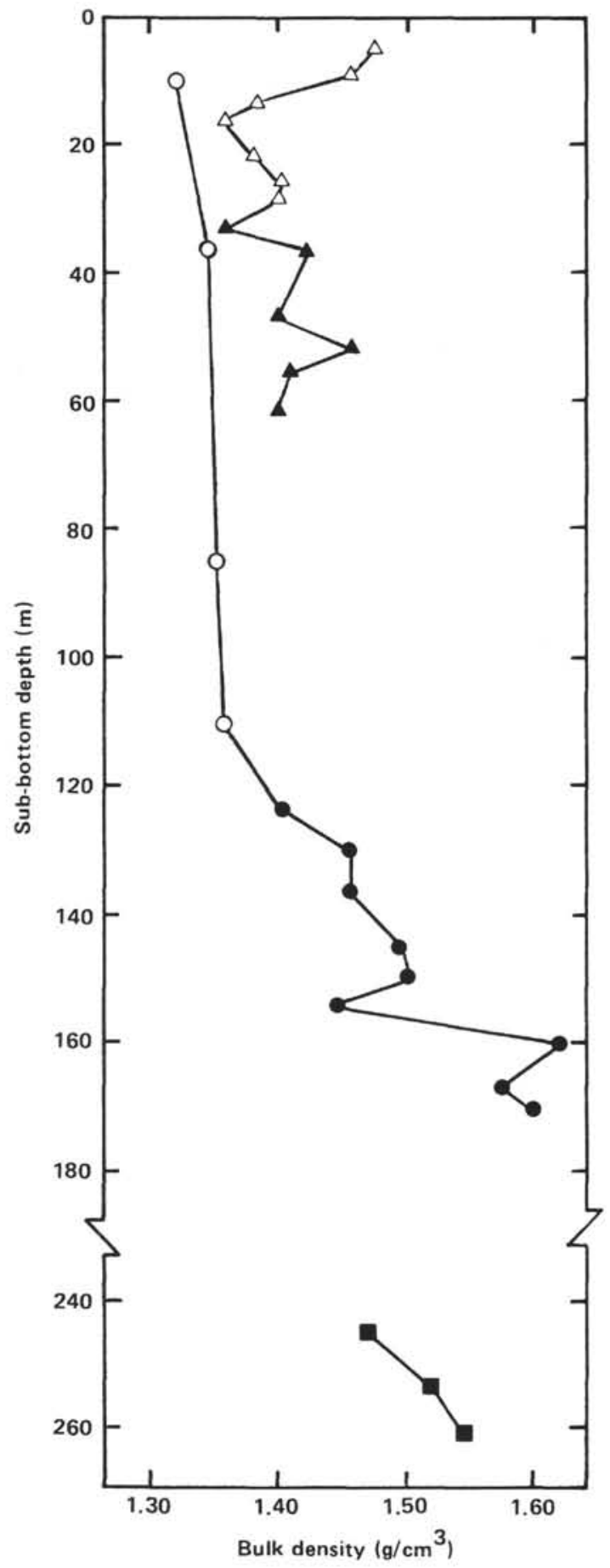

Figure 11. Bulk density as a function of depth for Holes 576, 578, and 581. Symbols as in Figure 3.

irregularities in sediment resistivity properties may be related to changes in sediment mineralogy. We will discuss this possibility in a later section, as well as the significance of the resistivity changes in the pelagic clay sediment with increasing burial depth.

\section{Acoustic Properties}

In this section we present vertical and horizontal compressional-wave velocity data and velocity anisotropy data for the clay mineral-rich sediments of Holes 576, 578,

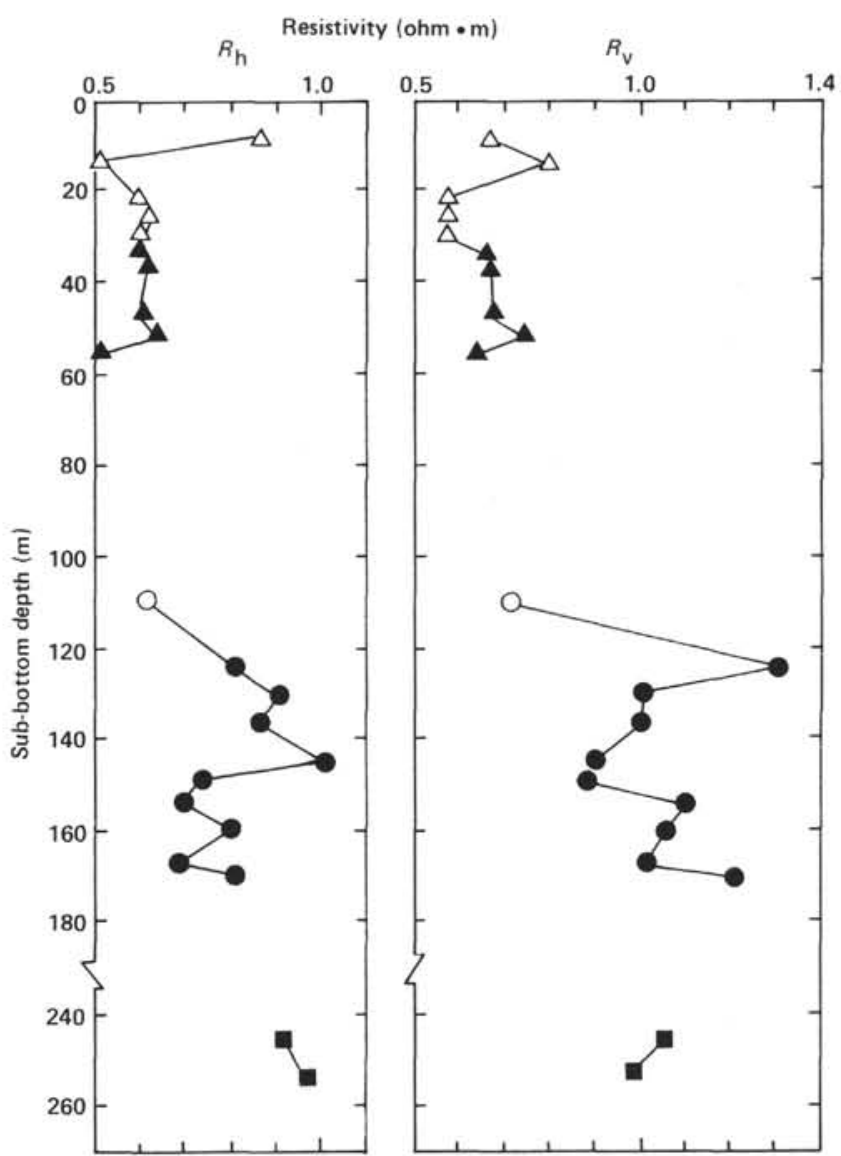

Figure 12. Electrical resistivity in both horizontal $\left(R_{\mathrm{h}}\right)$ and vertical $\left(R_{\mathrm{v}}\right)$ directions as a function of depth for Holes 576,578 , and 581. Symbols as in Figure 3.

and 581. Compressional velocity in isotropic material is related to bulk and shear moduli by the following equation (e.g., Birch, 1961; Boyce, 1981):

$$
V_{\mathrm{p}}=\left(\frac{K+4 \mu / 3}{\rho_{\mathrm{b}}}\right)^{1 / 2},
$$

where $V_{\mathrm{p}}$ is compressional velocity, $\rho_{\mathrm{b}}$ is wet-bulk density, $K$ is incompressibility or bulk modulus, and $\mu$ is shear modulus (rigidity). $K$ and $\mu$ may vary with direction in the sediment; therefore, sound traveling in the vertical and horizontal directions will have different velocities in an anisotropic sediment. Compressional velocity anisotropy is defined as

$$
A_{\mathrm{p}}(\%)=(100) \frac{V_{\mathrm{ph}}-V_{\mathrm{pv}}}{\overline{V_{\mathrm{p}}}}
$$

where $V_{\text {ph }}$ designates horizontal compressional-wave velocity, $V_{\mathrm{pv}}$ denotes vertical compressional-wave velocity, and $\bar{V}_{\mathrm{p}}$ is the mean compressional-wave velocity. It is anticipated, for a clay-size sediment undergoing compaction and collapse of fabric, that sound anisotropy may develop with velocity greater in the horizontal direction (Hamilton and Bachman, 1982).

Compressional-wave velocities and anisotropies in sediment and rock are related to a number of factors, usu- 


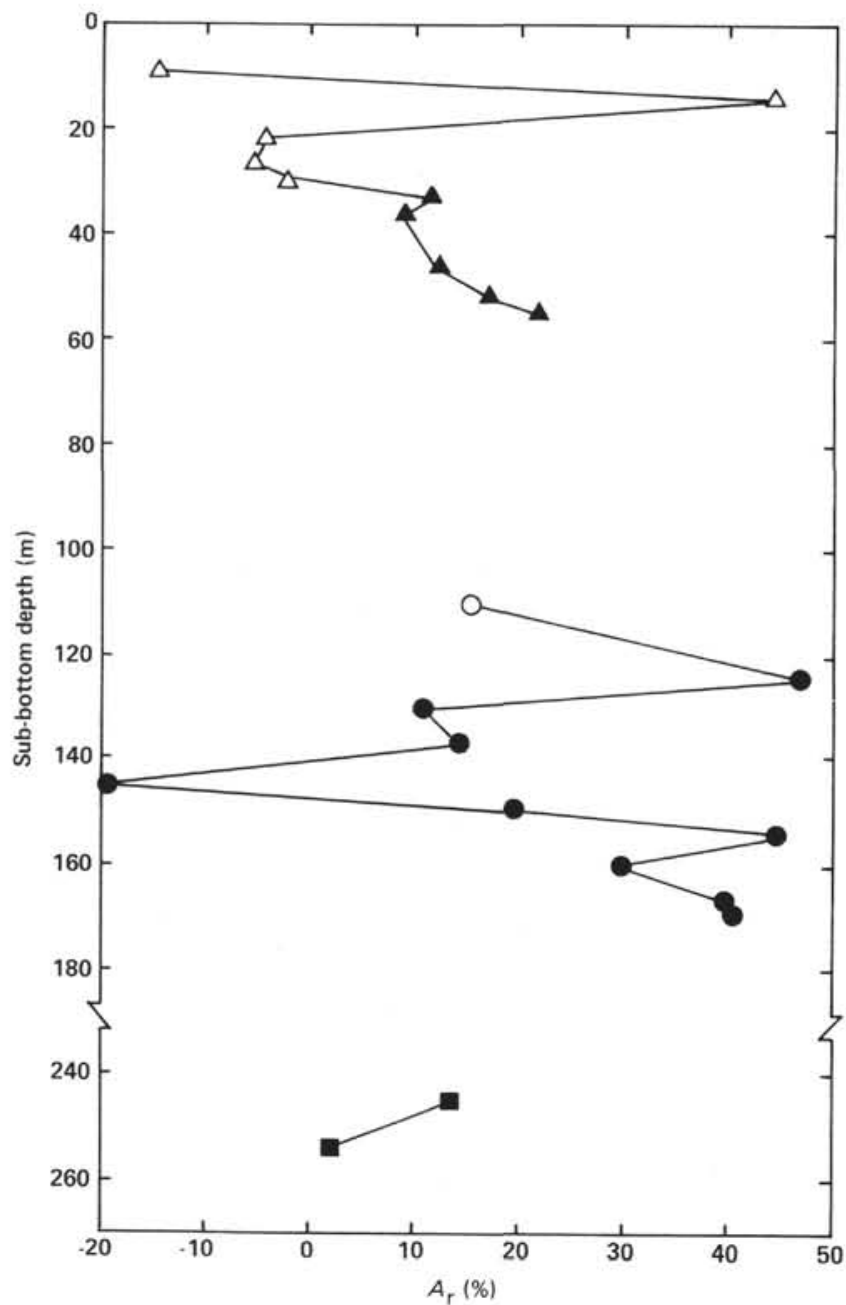

Figure 13. Resistivity anisotropy, $A_{\mathrm{r}}(\%)$, as a function of depth for Holes 576, 578, and 581. Symbols as in Figure 3.

Table 5. Electrical resistivity values for selected samples from Holes 576, 578, and 581.

\begin{tabular}{|c|c|c|c|c|}
\hline $\begin{array}{l}\text { Sample } \\
\text { (interval in } \mathrm{cm} \text { ) }\end{array}$ & $\begin{array}{l}\text { Sub-bottom } \\
\text { depth } \\
\text { (m) }\end{array}$ & $\underset{\text { (ohm-m) }}{R_{\mathrm{h}}}$ & $\underset{\text { (ohm-m) }}{R_{\mathrm{v}}}$ & $\begin{array}{c}A_{\mathrm{r}} \\
(\%)\end{array}$ \\
\hline $576-2-1,109-116$ & $8.29-8.36$ & 0.760 & 0.656 & -14.7 \\
\hline $576-3-3,109-115$ & $13.69-13.75$ & 0.512 & 0.798 & 43.7 \\
\hline $576-4-2,88-95$ & $21.48-21.55$ & 0.587 & 0.565 & -3.82 \\
\hline $576-4-5,98-104$ & $26.08-26.14$ & 0.605 & 0.569 & -6.13 \\
\hline $576-5-1,108-115$ & $29.28-29.35$ & 0.586 & 0.574 & -2.07 \\
\hline $576-5-6,18-25$ & $32.78-32.85$ & 0.579 & 0.647 & 11.1 \\
\hline $576-6-4,37-44$ & $36.27-36.34$ & 0.605 & 0.659 & 8.54 \\
\hline $576-7-2,130-137$ & $46.90-46.97$ & 0.591 & 0.667 & 12.1 \\
\hline $576-7-6,19-26$ & $51.79-51.86$ & 0.628 & 0.744 & 16.9 \\
\hline $576-8-1,98-105$ & $55.08-55.15$ & 0.503 & 0.628 & 22.1 \\
\hline $578-13-1,78-85$ & $110.08-110.15$ & 0.614 & 0.720 & 15.9 \\
\hline $578-14-4,53-60$ & $123.83-123.90$ & 0.809 & 1.311 & 47.4 \\
\hline $578-15-2,53-60$ & $130.33-130.40$ & 0.909 & 1.018 & 11.3 \\
\hline $578-15-7,28-34$ & $137.58-137.64$ & 0.872 & 1.004 & 14.1 \\
\hline $578-16-5,67-74$ & $144.47-144.54$ & 1.087 & 0.901 & -18.7 \\
\hline $578-17-2,72-79$ & $149.52-149.59$ & 0.728 & 0.888 & 19.8 \\
\hline $578-17-5,61-68$ & $153.91-153.98$ & 0.696 & 1.100 & 45.0 \\
\hline $578-18-3,38-45$ & $160.18-160.25$ & 0.800 & 1.068 & 28.7 \\
\hline $578-19-1,57-64$ & $166.87-166.94$ & 0.685 & 1.024 & 39.6 \\
\hline $578-19-3,53-60$ & $169.83-169.90$ & 0.809 & 1.222 & 40.6 \\
\hline $581-8-5,65-72$ & $245.15-245.22$ & 0.918 & 1.050 & 13.4 \\
\hline $581-9-4,33-40$ & $252.83-252.90$ & 0.967 & 0.986 & 1.9 \\
\hline
\end{tabular}

ally not independent, including pressure, temperature, mineralogical composition, fluid content, pore-water saturation, grain size, shape, and arrangement, and other variables (Press, 1966; Boyce, 1981). In a later section, we will discuss the effect of some of these variables on sound velocity in pelagic clay sediments from Holes 576, 578 , and 581 .

Figures 14 and 15 show laboratory-determined values of horizontal and vertical compressional-wave velocities and compressional-wave anisotropies, respectively. Table 4 gives data for these variables. In general, compressional-wave velocities, except for irregular velocities at depths shallower than about $20 \mathrm{~m}$, exhibit little change with increasing burial depth of the clay mineral-rich sediment sampled. There is, however, a slight, nearly linear, increase in $V_{\mathrm{ph}}$ in the brown pelagic clay with increasing burial depth: mean $V_{\mathrm{ph}}(\bar{x})$ increases from about 1.49 $\mathrm{km} / \mathrm{sec}$ at $30 \mathrm{~m}$ sub-bottom depth to about $1.55 \mathrm{~km} / \mathrm{sec}$ at a depth of $260 \mathrm{~m}$, equivalent to a $V_{\mathrm{ph}}$ gradient of $0.26 / \mathrm{sec}$ (Table 4 ). A poorly defined positive gradient of

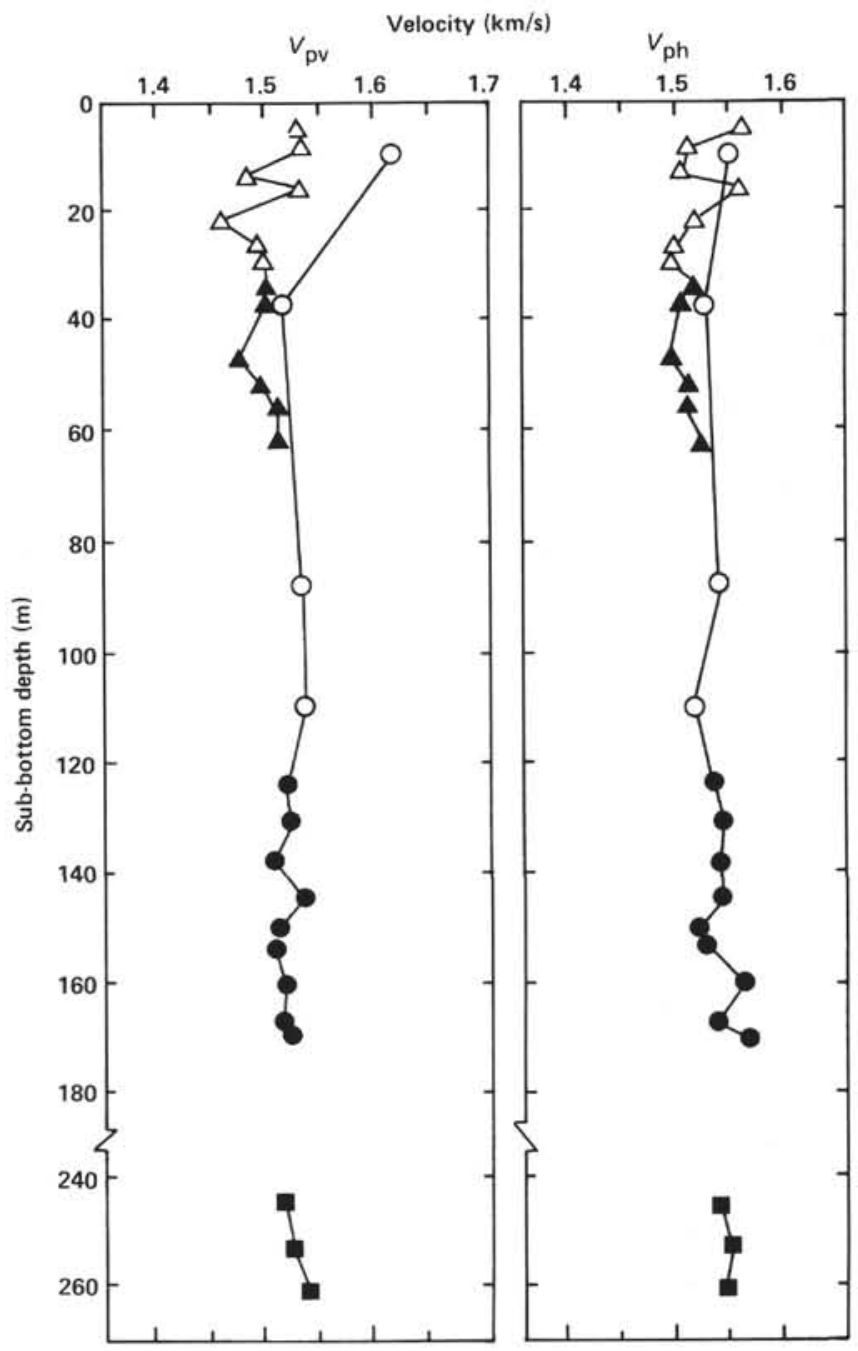

Figure 14. Compressional velocity in both vertical $\left(V_{\mathrm{py}}\right)$ and horizontal $\left(V_{\mathrm{ph}}\right)$ directions as a function of depth for Holes 576,578 , and 581. Symbols as in Figure 3. 


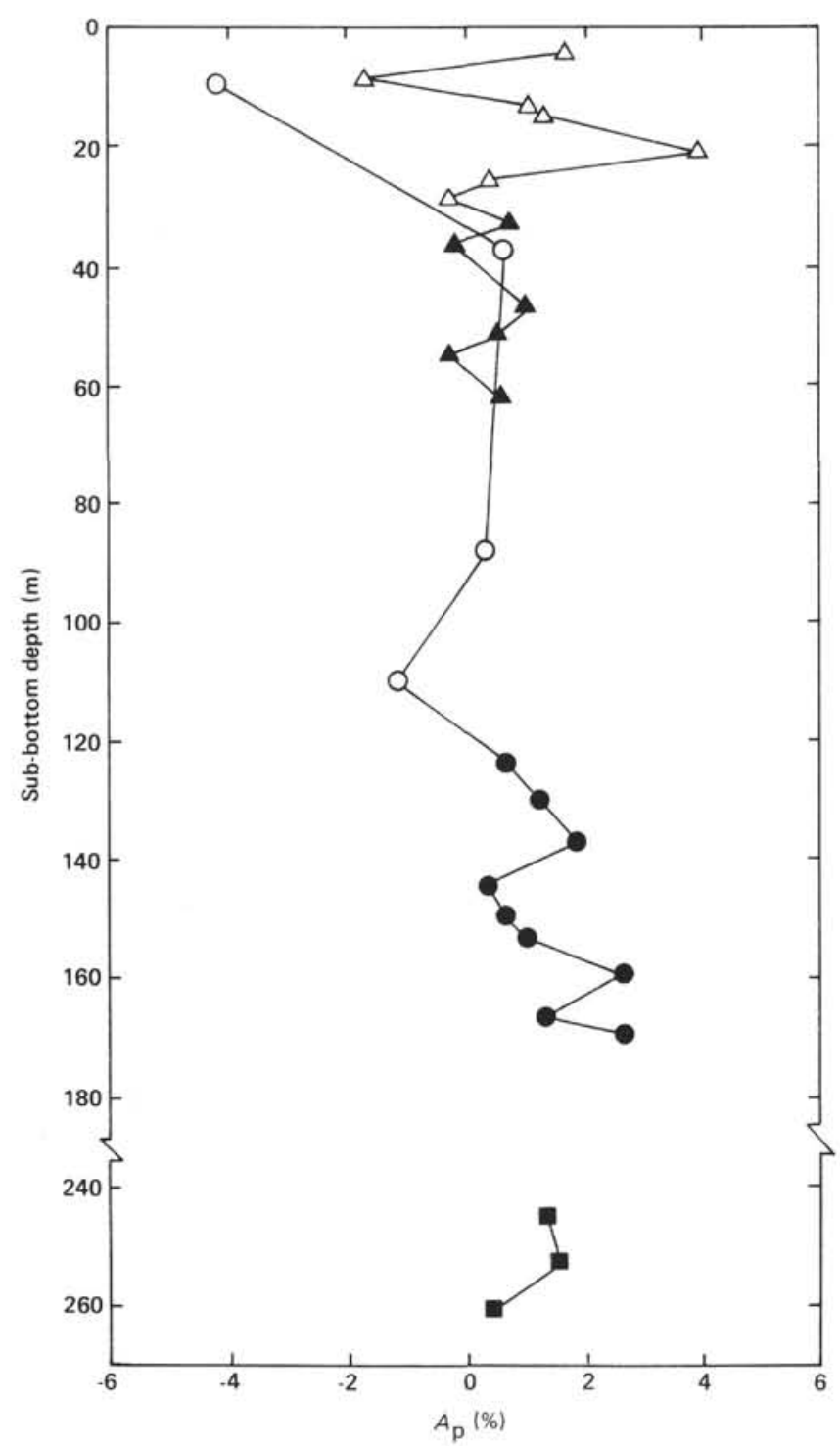

Figure 15 . Compressional velocity anisotropy, $A_{\mathrm{p}}(\%)$, as a function of depth for Holes 576, 578, and 581. Symbols as in Figure 3.

$V_{\mathrm{pv}}$ exists as a function of increasing burial depth of the brown pelagic clay. At Site 578, however, the change in $V_{\mathrm{pv}}$ with increasing depth of the brown pelagic clay is small.

Compressional-wave velocity anisotropy for these clay mineral-rich sediments is not large, varying from about -4 to $+4 \%$ (Fig. 15). Most anisotropy values tend to be positive or slightly negative. The observation that the brown pelagic clay develops velocity anisotropy at relatively shallow depths is of greater interest. Definite and persistent anisotropy starts at a saturated bulk density of $1.45 \mathrm{~g} / \mathrm{cm}^{3}$ at a sub-bottom depth of $130 \mathrm{~m}$. Stratigraphically higher pelagic clay samples show some anisotropy but the trend in $A_{\mathrm{p}}$ is not clear as in deeper sediment. There appears to be, at least in Hole 578, a general increase in sound velocity anisotropy with increasing depth of burial.

The three samples of brown pelagic clay from Site 581 again seem different. The values of $V_{\mathrm{pv}}, V_{\mathrm{ph}}$, and $A_{\mathrm{p}}$ for these samples are less than anticipated for the depth of burial of the samples.

\section{DISCUSSION}

\section{Characteristics of the Brown Pelagic Clay Unit}

As noted in the introduction, one goal of this study was to assess the effects of compaction on acoustic and electrical properties of pelagic clay. We have identified a unit of brown pelagic clay present at progressively deeper burial depths at Sites 576, 578, and 581. Because of this unit's chemical and mineralogical homogeneity, it is particularly well suited for evaluation of the changes in acoustic and electrical properties of pelagic clay resulting primarily from compaction. This homogeneous brown pelagic clay is characterized by: (1) a high clay mineral to quartz ratio, (2) a relatively high percentage of mixedlayer illite/smectite and low content of discrete illite, (3) the presence of palygorskite (at levels detectable by X-ray diffraction) in more than $50 \%$ of the samples, (4) high concentrations of $\mathrm{Fe}, \mathrm{Mn}, \mathrm{Cu}, \mathrm{Co}$, and $\mathrm{Ni},(5)$ few microfossils except ichthyoliths (see Doyle and Riedel, this volume), and (6) relatively high shear-wave velocity and vane-shear strength (see Schultheiss, this volume).

The upper boundary of this brown pelagic clay unit is transitional at all three sites, with the clay grading upward to a slightly silty mud that in some places is siliceous or contains abundant volcanic ash layers. The lower boundary is different at the three sites (see Site 576, 578 , and 581 chapters, this volume). In Hole 576, the brown pelagic clay unit is underlain by interbedded pelagic clay and carbonate ooze. The lower boundary of the brown pelagic clay unit at Site 578 appears to be at the base of the hole, where chert and foraminiferal mud were recovered in the core catcher of the stratigraphically lowest core. At Site 581, the brown pelagic clay unit is underlain by a mixture of pelagic clay and chert pebbles that grades downward to chert.

The approximate boundaries of the homogeneous brown pelagic clay unit are indicated on the stratigraphic cross section in Figure 16. These boundaries have been selected primarily on the basis of lithology and bulk mineralogy. Because of the transitional nature of the upper boundaries, precise locations are difficult to pick. It was felt that a criterion based on the clay/quartz ratio is a useful guide, and a cut-off of clay/quartz $>5$ was chosen (Fig. 4). Note that the depths of the boundaries chosen on this basis are similar, but do not correspond precisely, to lithologic boundaries based on color changes and smear-slide data noted in the site chapters (this volume).

The clay mineralogy and chemical data support the differentiation of the brown clay unit from overlying sediment. Because the upper boundaries are transitional and the distinction of the brown pelagic clay unit from overlying sediment probably reflects both original detrital and subsequent diagenetic differences, the precise location of the upper unit boundaries would vary somewhat if clay mineralogy or chemistry were used as selection criteria. In addition, the mineralogical and chemical data for Site 578 (Fig. 6; Table 3) suggest that the lower 


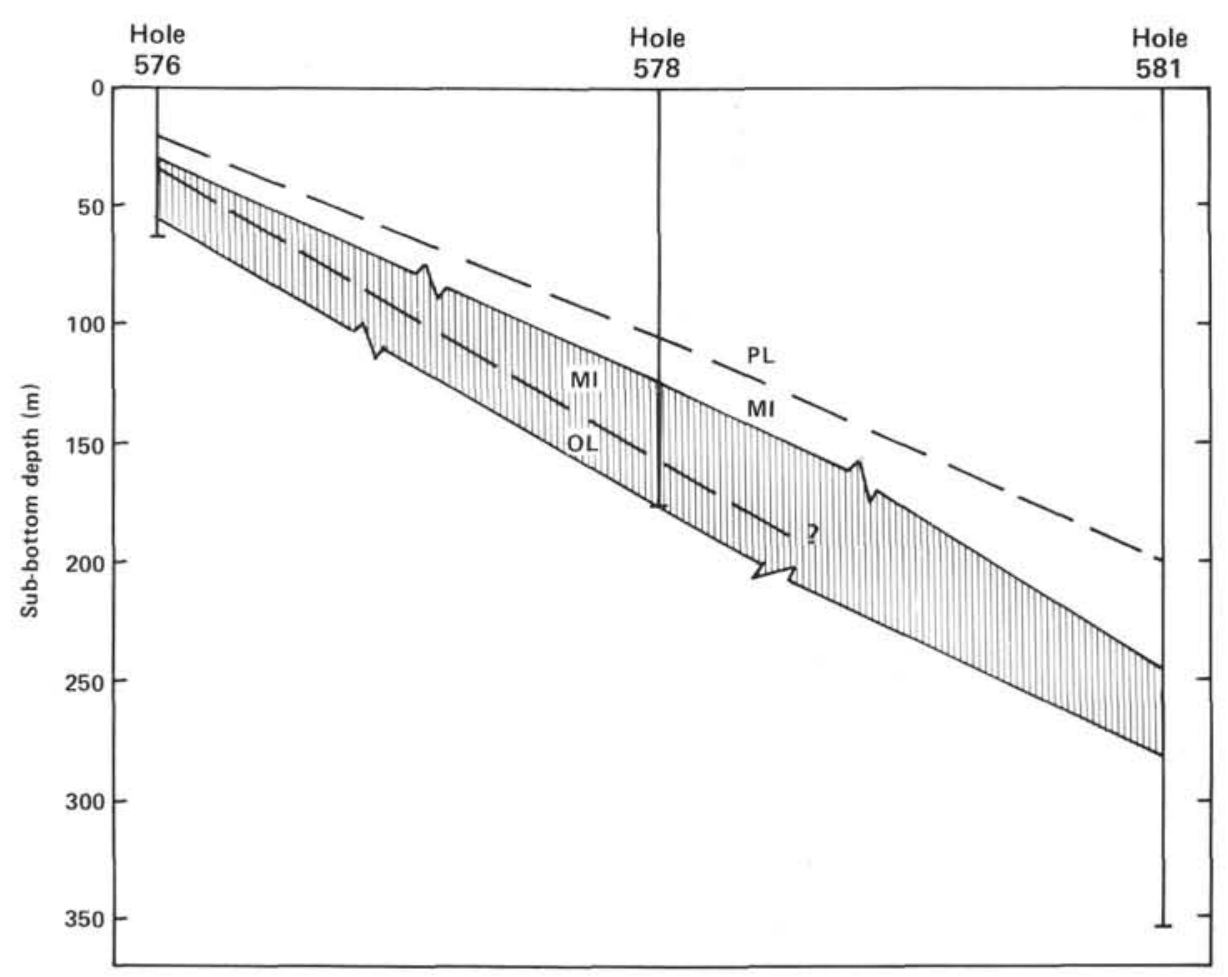

Figure 16. Cross-section depicting boundaries (solid lines) of the brown pelagic clay unit (hachured) at Sites 576, 578, and 581. Dashed lines are time lines indicating approximate locations of the Pliocene/Miocene (PL/MI) and Miocene/Oligocene (MI/OL) boundaries.

boundary of the brown pelagic clay unit may also be transitional and that, with more detailed study, an additional unit could be defined near the base of that site. Because our clay/quartz criterion does not support differentiation of an additional unit, however, we extend the lower boundary of the brown pelagic clay unit in Hole 578 to the core catcher of the deepest core.

The time lines indicated on Figure 16 were approximately located using paleomagnetic data (see Heath, Rea, and Levi, this volume), ichthyolith data (Doyle and Riedel, this volume), and microfossil data (Site 576, 578, and 581 chapters, this volume). At Sites 576 and 578, the homogeneous brown pelagic clay unit is underlain by Upper Cretaceous sediment, and the transition from deposition of pelagic clay to deposition of more silty mud occurred sometime in the Miocene. The sparse age data for the brown pelagic clay at Site 581 indicate a Miocene or older age. Thus, the brown pelagic clay units at each of the three sites appear to be roughly age equivalent.

The transition from the silty, sometimes siliceous, mud to the brown pelagic clay unit below probably represents both a change in original detrital mineralogy and an overprint of diagenesis. Thus, this transition provides an opportunity for evaluation of the possible effects of mineralogy, chemistry, and diagenesis on the electrical and acoustic properties of pelagic clay, a second goal of this project. The evidence for changes in detrital mineralogy and diagenetic imprint across the lithologic transition will be reviewed next. We will then consider the influence of compaction (i.e., depth of burial), mineralogy, chemistry, and degree of diagenetic alteration on acoustic and electrical properties of pelagic clay.

\section{Detrital versus Diagenetic Imprint}

Leinen (this volume) and Janecek (this volume) provide independent estimates of mass-accumulation rates of quartz and other eolian material, respectively, for Site 576. Their data indicate low eolian mass-accumulation rates for sediment below about $30 \mathrm{~m}$ sub-bottom depth, with a rapid rise to high values for sediment in the upper $10-12 \mathrm{~m}$. They suggest the rapid increase in eolian massaccumulation rates corresponds to movement of Site 576 into the zone of prevailing westerlies. Our bulk mineralogy data for Site 576 (see Fig. 3) reflect the change in eolian mass-accumulation rates. The homogeneous brown pelagic clay unit, having high total clay mineral content and low quartz and feldspar contents, was deposited during the period of low eolian mass-accumulation rates. As Site 576 moved northwest into the zone of the westerlies, the relative percentages of quartz and feldspar increased. Bulk mineralogical data for Site 578 (Fig. 3) indicate an analogous situation.

Clay mineralogy data for Site 576 are also consistent with an increase in eolian mass-accumulation rates at relatively shallow burial depths. The percentages of illite, kaolinite, and chlorite, all of which probably reflect a detrital signal, increase upsection (Fig. 5). The case for Site 578 appears more complicated. Although changes in sample compositions expressed in percentages do not necessarily indicate variations in mass-accumulation rates for all components, the relatively high contents of illite, 
kaolinite, and chlorite in the basal $20-25$ m of Hole 578 may indicate an early period of high eolian mass-accumulation rates (Fig. 6). Immediately above this basal zone, the presumed detrital minerals are present in low concentrations and then their percentages increase upsection. Thus, it appears that the low contents of quartz and other probable eolian minerals in the homogeneous brown pelagic clay unit compared to overlying muds reflect original detrital differences related to changes in eolian mass-accumulation rates.

In addition to changes in mass-accumulation rates, the eolian flux of material to the sites may have changed in composition as the sites moved north and northwest with time. Oscillations in the relative proportions of mixed-layer illite/smectite and illite at Sites 576 and 578 (Figs. 5 and 6), for example, could possibly reflect variations in the composition of the eolian flux of clay minerals to the sites, as has been suggested by Lenotre et al. (this volume). Various lines of evidence suggest, however, that diagenetic alteration of the sediments has influenced their clay mineralogy and chemistry and may be responsible for some of the observed compositional variations.

For example, it was noted earlier (Figs. 5 and 6) that the composition of the mixed-layer illite/smectite varies downsection in Holes 576 and 578, and that samples with high percentages of illite/smectite tend to have fewer illite interlayers in the mixed-layer clay. Hein et al. (1976), Hein and Scholl (1978), and Vallier and Kidd (1977) presented guidelines for determining whether or not fine-grained sediment has had a significant volcanogenic source. In general, muds or mudstones derived from alteration of volcanic debris are likely to contain high percentages of smectite which has relatively few $(<15-20)$ illite interlayers. A clay mineral-rich sediment made up of $>75 \%$ smectite is thought to be mostly volcanogenic in origin; one containing $50-75 \%$ smectite is suspected of having a significant volcanogenic component. Furthermore, Hein et al. (1976) noted that as the percentage of smectite in Bering Sea sediment declined, the number of illite interlayers increased to the background level of $45-50 \%$ illite interlayers, a composition representative of the terrigenous input in that area. Following these guidelines, a number of the samples analyzed in this study are thought to have a significant volcanogenic component. Figures 5, 6, and 7 show that many samples contain more than $50 \%$ illite/smectite and several more than $70 \%$. If the samples containing the least amount of illite/smectite are considered representative of the terrigenous input, that illite/smectite contains about $40-50 \%$ illite interlayers. In most places, the samples richest in illite/smectite contain fewer than $25 \%$ illite interlayers. Thus, these samples, although not dominantly volcanogenic, probably contain a significant volcanic component. Almost all the samples with suspected volcanic origins fall within the brown pelagic clay unit. The more silty muds overlying this unit contain dominantly terrigenous illite/smectite. Disseminated volcanic glass and volcanic ash layers were noted in smear-slide examinations of sediments from Sites 576 and 578 (see Site 576 and 578 chapters, this volume), particularly from the silty mud overlying the brown clay unit. The presence of this material documents the volcanic influx to the sediment and suggests that in the younger sediment, diagenesis has not yet altered the volcanic debris to smectite and associated minerals.

Additional evidence of a diagenetic imprint on the brown pelagic clay unit can be seen in the chemical data. As was noted earlier, $\mathrm{Fe}_{2} \mathrm{O}_{3}, \mathrm{MnO}$, and associated trace metals typical of authigenic amorphous $\mathrm{Fe}$ - and Mn-oxyhydroxides are more abundant in the brown clay unit than in overlying deposits (see Table 3). The changing influence of detrital versus diagenetic components in the sediments of Leg 86 is shown in Figure 17. As one moves downhole at each site, the detrital component (represented by the sum of quartz plus feldspar) declines in abundance whereas the authigenic metal phases increase.

Palygorskite, which may be another diagenetically produced phase, was detected in samples from the brown pelagic clay units of Holes 576 and 578. As shown in Figures 5 and 6, palygorskite increases in abundance downhole at these two sites. Although palygorskite may be detrital, in many deep-sea sediments it is believed to have formed authigenically either by the action of $\mathrm{Mg}$ rich hydrothermal solutions on sediments overlying basalt or by the low temperature alteration of volcanic debris, perhaps with smectite as an intermediate product (Elderfield, 1976; Couture, 1977). Phillipsite, another common product of alteration of volcanic debris, was noted in one sample (Sample 576-5-6, 18-25 cm; see Plate 1).

It should be noted that, in general, the results of our mineralogical analyses are very similar to those of Lenotre et al. (this volume), who studied the clay stratigraphy of Sites 576 and 578. Those authors favor a changing detrital supply, with minimal diagenetic effects, as an explanation of the observed mineralogical variations. Their conclusion is drawn primarily on the bases of transmission electron microscope observations of clay morphology and mineral associations. We feel, however, that

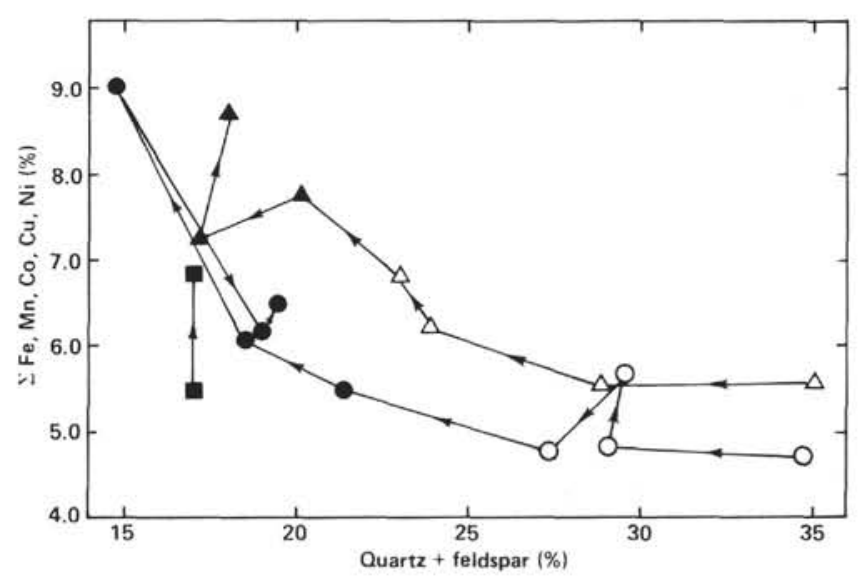

Figure 17. Metal content (summation of $\mathrm{Fe}, \mathrm{Mn}, \mathrm{Co}, \mathrm{Cu}$, and $\mathrm{Ni}$ in $\%$ ) plotted versus the summation of quartz plus feldspar content for samples from Holes 576, 578, and 581. Arrows point in a downhole direction for each hole, indicating the downhole enrichment in metals and depletion in quartz plus feldspar. Symbols as in Figure 3. 
our observations of the correlation of abundance and composition of illite/smectite mixed-layer clay; the abundance of $\mathrm{Fe}, \mathrm{Mn}$, and associated trace metals; and the presence of palygorskite suggest that the diagenetic imprint on sediment composition is significant, particularly in the brown pelagic clay unit identified in Holes 576, 578 , and 581 .

\section{Relationships between Resistivity and Other Sediment Properties}

In this section we discuss relationships between resistivity, acoustic velocity, and clay sediment chemistry and mineralogy. Emphasis is on the brown pelagic clay unit. We will demonstrate that it is primarily the physical process of compaction that affects the depth-related acoustic and electrical response of the brown pelagic clay unit; initial detrital mineralogy and subsequent diagenesis play minor roles.

\section{Resistivity Correlations}

Sediment resistivity can be expressed as the product of a formation factor, $F$, and the resistivity of the interstitial water, $R_{\mathrm{w}}$. Measured resistivities, therefore, will reflect changes in variables affecting $F$ (e.g., porosity, fabric, texture, mineralogy) and $R_{\mathrm{w}}$ (e.g., salinity, temperature). For marine sediment, the assumption is usually made that pore waters have constant salinities equal to that of the overlying bottom water. Although this is certainly not always the case, it appears to be a good approximation for Sites 576,578 , and 581 . The pore-water data (see Site 576, 578, and 581 chapters, this volume) show that all salinities measured at these three sites fall between 34.5 and $35.5 \%$. At the temperature of measurement $\left(23^{\circ} \mathrm{C}\right)$, a $1 \% 0$ salinity variation would result in less than a $0.01 \mathrm{ohm}-\mathrm{m}$ change in resistivity of the pore water. We have, therefore, assumed a constant value of 0.19 ohm-m for $R_{\mathrm{w}}$ (Schlumberger, 1958; Boyce, 1968). Observed variations in measured sediment resistivity can therefore be assumed to reflect changes in the sediment (i.e., changes in the formation factor, $F$ ).

Porosity, and therefore water content, should vary inversely with resistivity. Although porosity was not measured in our laboratory, these data are available from Schultheiss (this volume). To investigate correlations between resistivity and porosity, we used porosity data for samples from the same core, and whenever possible the same section, as the samples on which resistivity measurements were made. Resistivity parallel to bedding $\left(R_{\mathrm{h}}\right)$ and perpendicular to bedding $\left(R_{\mathrm{v}}\right)$ is roughly correlated with porosity (Figure 18). As expected, this relationship seems better developed for $R_{\mathrm{v}}$ than for $R_{\mathrm{h}}$. During burial, the reduction in porosity and the reorientation of clay mineral particles both act to increase resistivity in the vertical direction. On the other hand, the alignment of grains and pore spaces with long axes lying in a horizontal plane lowers resistivity somewhat in the horizontal direction and tends to counterbalance some of the resistivity increase owing to porosity reduction. Similar relationships were found between resistivity and water content (data from Schultheiss, this volume). Resistivity an-
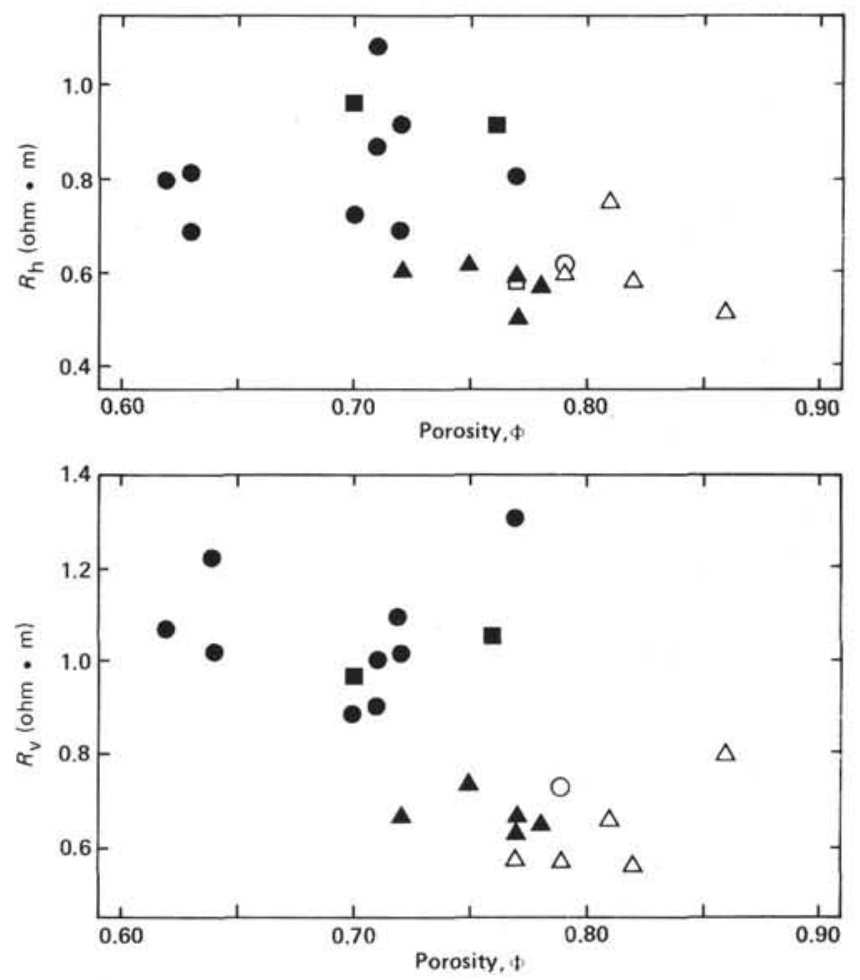

Figure 18. Horizontal $\left(R_{\mathrm{h}}\right)$ and vertical $\left(R_{\mathrm{v}}\right)$ resistivity as a function of porosity $(\Phi)$ for samples from Holes 576,578 , and 581 . Symbols as in Figure 3.

isotropy shows only a weak inverse correlation with porosity.

The resistivity-porosity relationship is shown on a loglog plot in Figure 19. A linear fit to these data yields the following expression:

$$
R_{\mathrm{o}}=0.46 \Phi^{-1.65} \text {. }
$$

Division of the above expression for $R_{\mathrm{o}}$ by the resistivity of the pore water $\left(R_{\mathrm{sw}}=0.19\right)$ yields the formation factor:

$$
\frac{R_{\mathrm{o}}}{R_{\mathrm{sw}}}=F=2.4 \Phi^{-1.65} .
$$

The value of the constant, $m(1.65)$, is slightly less than values obtained by Boyce (1968) and Kermabon et al. (1969) for silty muds and marine muds and turbidite sands. Separate regressions for $R_{\mathrm{v}}$ and $R_{\mathrm{h}}$ yield similar expressions with the constant, $m$, equal to 1.98 and 1.33 , respectively. Note that the linear fit to the data does not fulfill a boundary condition required by physical considerations (Fig. 19). That is, for a porosity of $100 \%$ $(\log \phi=0)$ the resistivity should be that of the interstitial water. In other words, at $\log \phi=0, \log R_{\mathrm{o}}$ should equal $-0.7\left(\log R_{\mathrm{sw}}\right)$. This discrepancy perhaps indicates that the linear fit cannot be extended to high porosities and that the data should properly be fit with a curvilinear expression. Another possible explanation for the discrepancy centers on the two sources of the data 


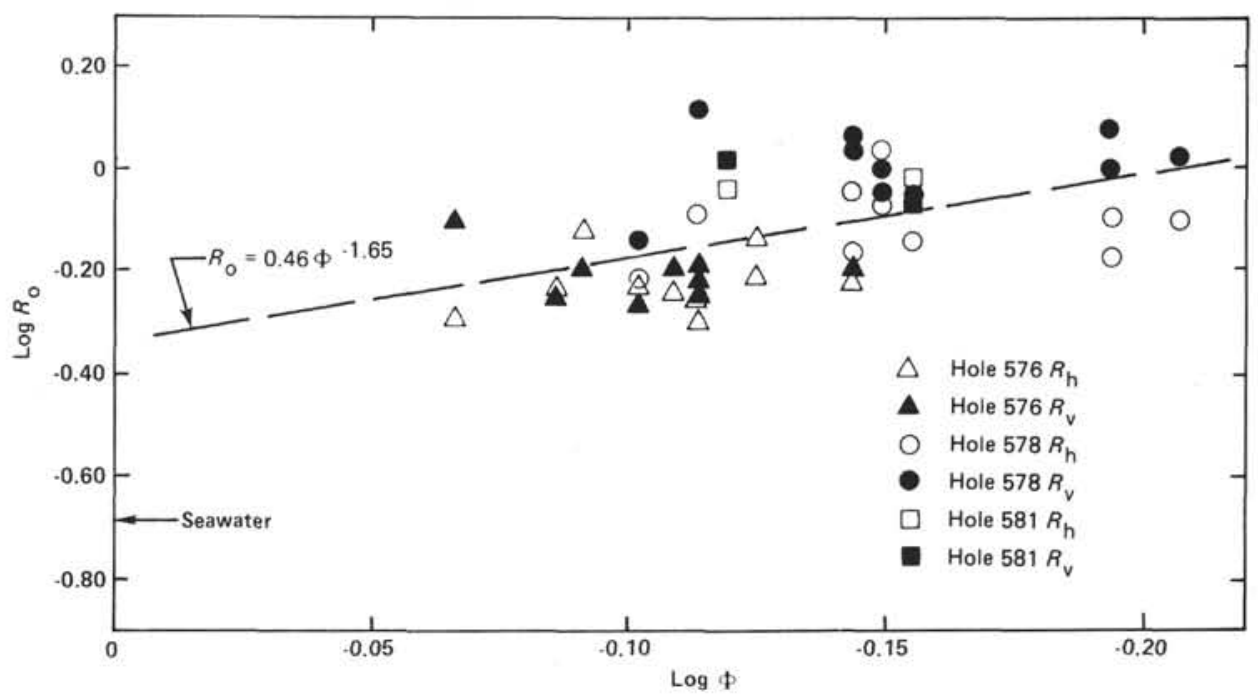

Figure 19. Log resistivity, $R_{\mathrm{o}}$, (both horizontal and vertical) as a function of log porosity $(\Phi)$. Dashed line gives the least squares fit to the data $\left(r^{2}=0.533\right)$. $\log R_{\mathrm{o}}$ for seawater is indicated by the arrow.

involved. Porosities were obtained from measurements made on shipboard, soon after core recovery. The resistivities, however, were measured in our laboratory approximately $1.5 \mathrm{yr}$. after Leg 86 took place. It is possible that partial dehydration of the cores during that time period resulted in increased resistivities and, when those data are plotted against shipboard porosities, an offset results.

Another factor that influences the resistivity of a sediment is its fabric; the size, shape, and nature of packing of grains affect how electricity will flow through a sediment. The ratio of clay/quartz can be used as a general indicator of changes in fabric, as well as changes in mineralogy. There are two roughly parallel trends of decreasing $R_{\mathrm{y}}$ with increasing clay/quartz ratio, one established by the samples within the brown pelagic clay unit and the other for the overlying mud (Fig. 20). The existence of two separate trends is difficult to explain. Depth of burial does not appear to be responsible because the two trends have overlapping depth ranges. The explanation presumably lies in compositional differences (either mineralogical or chemical) between the two types of sediment. The brown pelagic clay unit samples have higher contents of $\mathrm{Fe}$ and other metallic elements. The presence of metallic minerals, however, tends to decrease resistivity (Boyce, 1981; Keller, 1966), which would not explain the separate trends of Figure 20. Because the mineralogical variations between the two types of clay are transitional, it is unlikely that concentration of a particular mineral could cause the separate trends. More likely, a combination of factors, perhaps including content of water, microfossils, volcanic debris, and mineralogical and chemical make-up, results in separation of the trends of $R_{\mathrm{v}}$ versus clay/quartz ratio. It is also possible that analysis of more samples would lead to delineation of a transition between the two trends of Figure 20 .

The relationships between $R_{\mathrm{h}}$ and resistivity anisotropy and the clay/quartz ratio are not so well established. The weak correlations are similar, however, to that of $R_{\mathrm{v}}$ versus clay/quartz, with $R_{\mathrm{h}}$ and $A_{\mathrm{r}}$ decreasing with in-

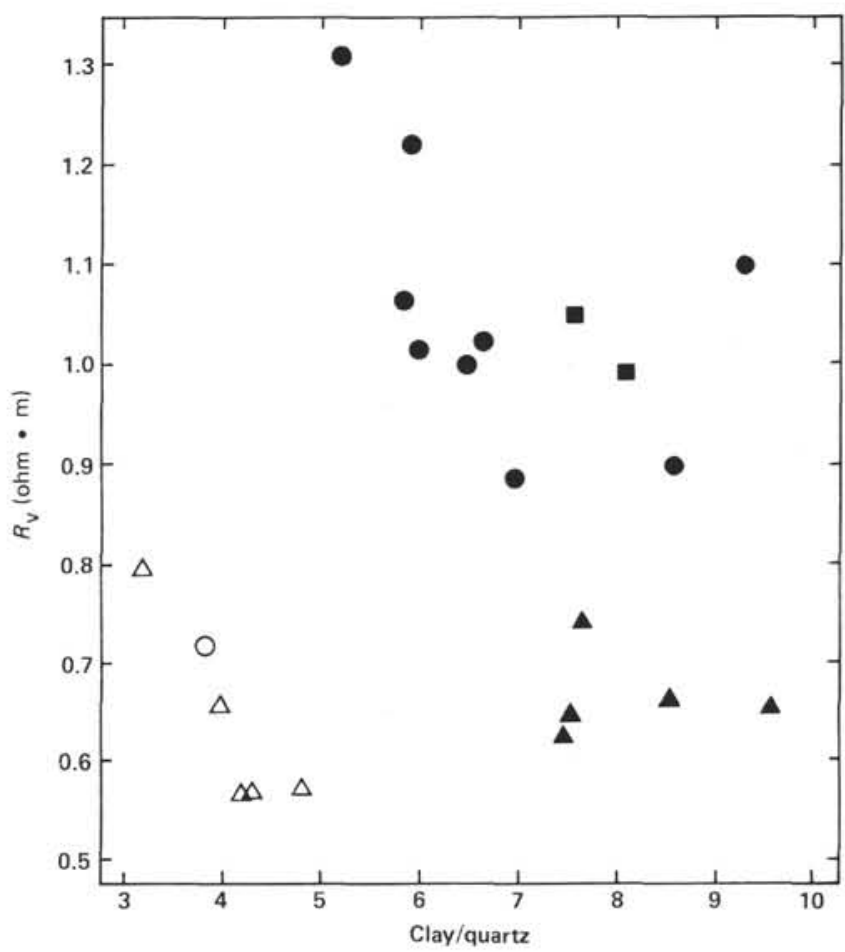

Figure 20. Vertical resistivity $\left(R_{\mathrm{y}}\right)$ as a function of the clay/quartz ratio for samples from Holes 576, 578, and 581. Symbols as in Figure 3.

creasing clay/quartz ratio. Separate trends for the brown clay unit and the overlying clays may exist.

Different clay minerals are known to have different electrical resistivities. This variability is due largely to their cation exchange capacities. Clay minerals that exchange or remove ions from solution surround themselves with an ionic cloud that can be highly conductive. Smectite, because of its net negative layer charge and high water content, would tend to have lower electrical resistivity than many other clay minerals. With this in mind, we attempted to determine if resistivity is corre- 
lated with specific clay mineralogy. No correlations with mineralogy (other than with clay/quartz as already discussed) could be found. Perhaps the observed mineralogical variations are not of significant magnitude to generate a response in resistivity properties, or such response is overshadowed by the dominant effects of compaction (porosity loss) and texture change (clay/quartz ratio).

\section{Acoustic Property Correlations}

The incompressibility (bulk modulus) of surficial deepsea sediments varies with porosity and therefore with density (Hamilton, 1971). Sediment bulk moduli increase with decreasing porosity and increasing bulk density. Because compressional-wave sound velocity $V_{\mathrm{p}}$ is directly related to the sediment bulk modulus by

$$
\rho V_{\mathrm{p}}^{2}=K+4 \mu / 3
$$

a positive correlation between $V_{\mathrm{p}}$ and $\rho$, and a negative correlation between $V_{\mathrm{p}}$ and $\Phi$, would be anticipated for the clay mineral-rich sediment of this study. Furthermore, the observed general trends of porosity and density with increasing burial depth (negative gradient of porosity, positive gradient of density) should lead to an increase in bulk moduli and rigidity (Hamilton, 1971) with increasing depth. That the sediment has rigidity is demonstrated by the observation that it transmits shear waves even at high porosities (shallow depths). Shear-wave velocities tend to increase, somewhat irregularly, with increasing burial depth (Schultheiss, this volume). Thus, a positive gradient of $V_{\mathrm{p}}$ would be anticipated for the clay mineral-rich sediment as a function of depth (Fig. 14).

Correlations of $V_{\mathrm{pv}}$ and $V_{\mathrm{ph}}$ with porosity are not strong, probably accounting in part for the small gradient in $V_{\mathrm{p}}$ as a function of burial depth (Fig. 21). It is apparent that the $V_{\mathrm{p}}-\Phi$ relationship is poor at high porosities (shallow depths), but is fair in the brown pelagic clay at lower porosities (deeper depths). The trend of $V_{\text {ph }}$ with porosity for the brown pelagic clay is more apparent than that of $V_{\mathrm{pv}}$. Thus, the positive gradient of $V_{\mathrm{ph}}$ with burial depth is steeper than that of $V_{\mathrm{pv}}$ (Fig. 14).

$V_{\mathrm{p}}$ anisotropy, particularly in the brown pelagic clay, with $V_{\mathrm{ph}}$ generally greater than $V_{\mathrm{pv}}$, is also weakly correlated to porosity; decreasing porosity generally results in increasing positive anisotropy (Fig. 22). In general a decrease in sediment porosity is reflected in an increase in density. Thus, there are weak positive correlations between density and velocity (Fig. 23) and density and anisotropy (cf. Figs. 11 and 15). The trend with density is more apparent for $V_{\mathrm{ph}}$ than $V_{\mathrm{pv}}$. The two regression lines on Figure 23 are those calculated by Hamilton (1978) for surficial seafloor sediments and for soft sediment buried to depths less than $500 \mathrm{~m}$. The trend for seafloor sediment is very similar to that for all the velocity data obtained by us in the laboratory.

Sound velocity in seawater at laboratory conditions of $23^{\circ} \mathrm{C}$ and $1 \mathrm{~atm}$. pressure is $1.53 \mathrm{~km} / \mathrm{sec}$. Many of the clay mineral-rich sediments have velocities less than that in seawater (Fig. 21). Also, as mentioned above, there appears to be greater scatter of velocities at higher porosities than at lower, with velocities ranging from $2 \%$ greater than to $5 \%$ less than that of seawater at po-
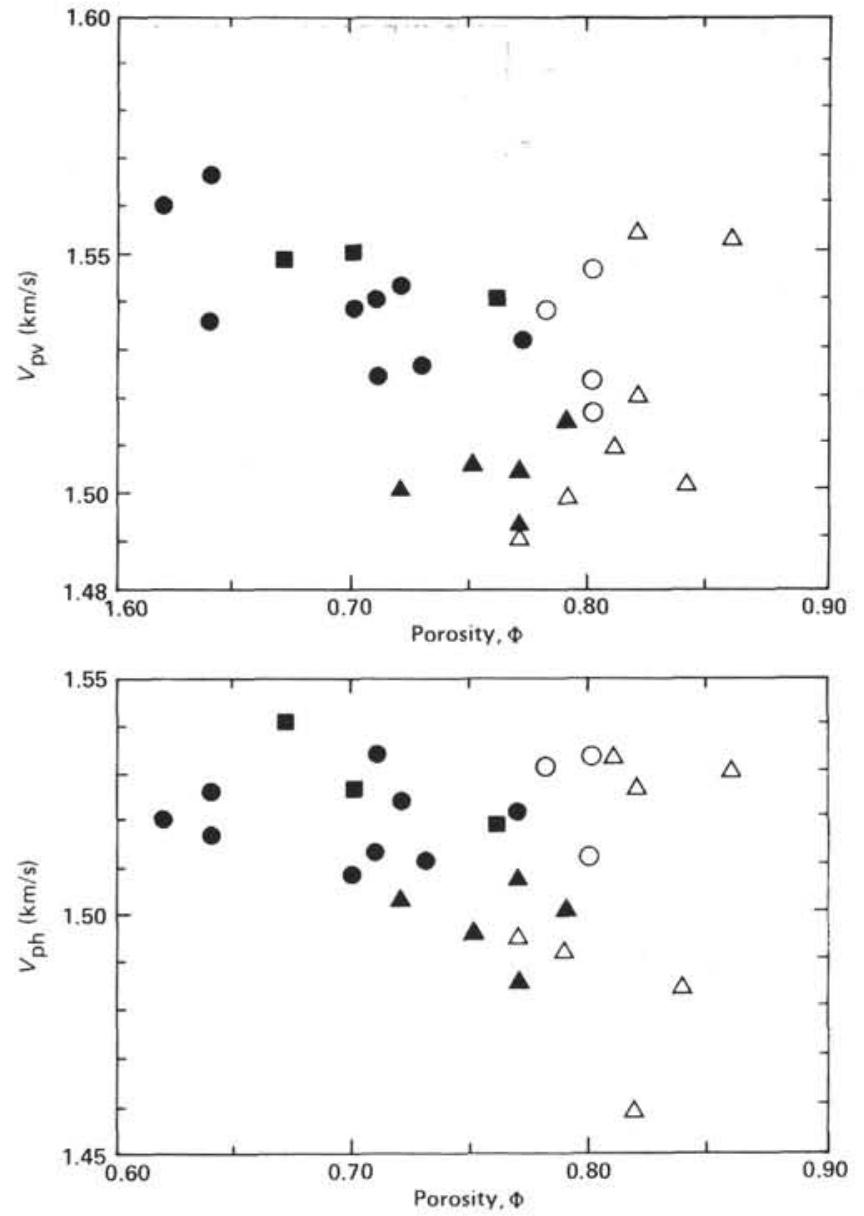

Figure 21. Horizontal $\left(V_{\mathrm{ph}}\right)$ and vertical $\left(V_{\mathrm{pv}}\right)$ compressional velocity versus porosity $(\Phi)$. Symbols as in Figure 3.

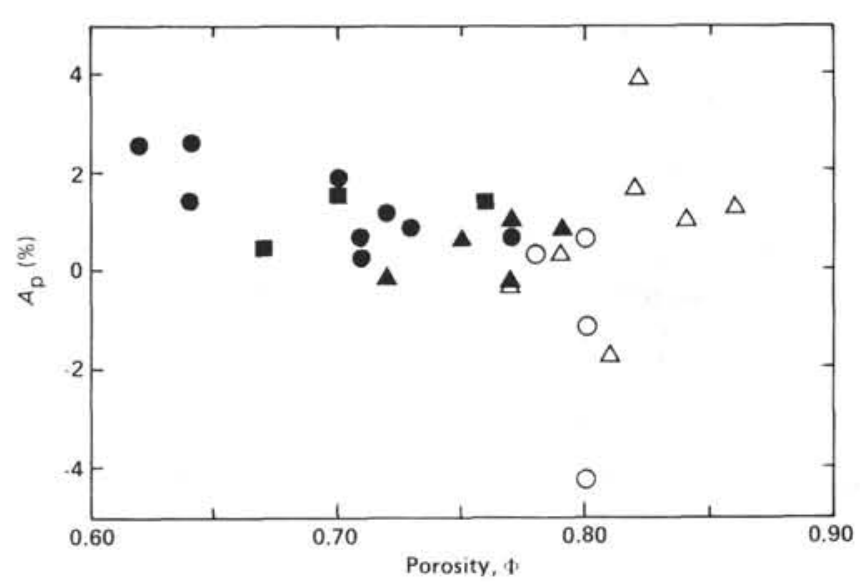

Figure 22. Compressional velocity anisotropy $\left(A_{\mathrm{p}}\right)$ as a function of porosity $(\Phi)$. Symbols as in Figure 3.

rosities greater than $80 \%$. The low-velocity effect is probably a result of the low rigidity of the high porosity sediment and the high compressibility (low bulk modulus) of seawater relative to mineral moduli (Hamilton, 1971).

Aside from the correlations shown in Figures 21, 22, and 23 , no definitive correlation was obtained for $V_{\mathrm{pv}}$, $V_{\mathrm{ph}}$, or $A_{\mathrm{p}}$ as a function of chemical or mineralogical independent variables. Perhaps some of the scatter in sound 


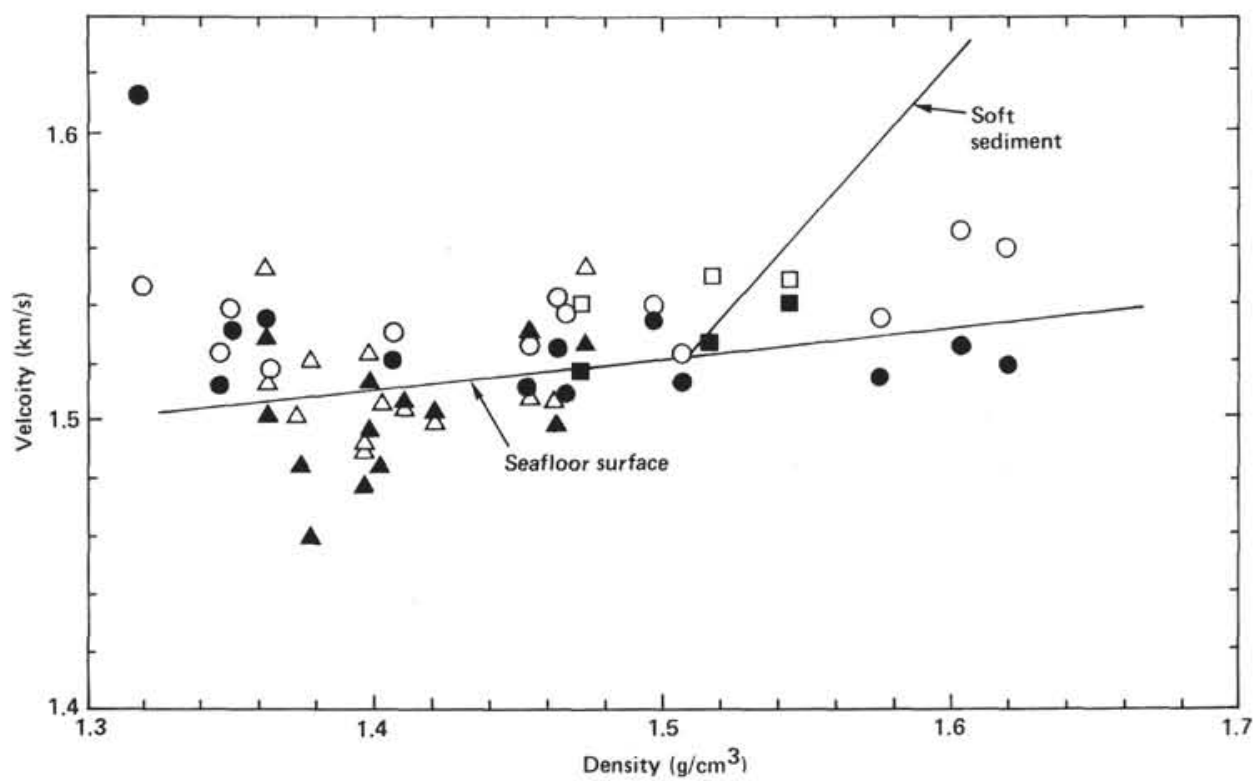

Figure 23. Compressional velocity versus density. Lines indicating trends for seafloor surface and soft sediments are from Hamilton (1978). Symbols as in Figure 3.

properties of the clay mineral-rich sediment at high porosities is due to minor admixtures of opaline silica and volcanogenic material. Certainly volcanic ash layers, not sampled by us, exhibit relatively high compressional-wave velocities (Schultheiss, this volume).

We believe that the changes in acoustic properties of the brown pelagic clay with burial depth are principally due to physical processes. Increasing overburden pressure results in preferred reorientation of the clay mineral particles with long axes normal to the pressure, reduction in porosity (water content), and increasing bulk density. Because of these changes, with increasing depth of burial, sound velocity increases and velocity anisotropy develops with velocity greater parallel to the seafloor.

\section{Correlations between Resistivity and Acoustic Properties}

This discussion will be restricted to the brown pelagic clay unit, for which reasonably well-defined relationships exist between resistivity and acoustic properties and burial depth. In general the positive gradient of $V_{\mathrm{ph}}$ with burial depth is correlated with a positive gradient of $R_{\mathrm{v}}$. Although values of $V_{\mathrm{pv}}$ and $R_{\mathrm{h}}$ also seem to increase with burial depth, the trend is not as definite or as steep. To a first approximation these gradients are related to a decrease in porosity, and thus increase in bulk density, of the clay mineral-rich sediment with increasing burial depth.

Of particular interest is the positive correlation between resistivity anisotropy and compressional-wave velocity anisotropy (Fig. 24). In general anisotropies increase with porosity decrease and bulk density increase, hence burial depth. There are exceptions to the general trend. It appears to be true, however, that with increasing burial depth positive anisotropies of increasing magnitude become more the rule than the exception. Thus, with increasing burial depth the brown pelagic clay de-

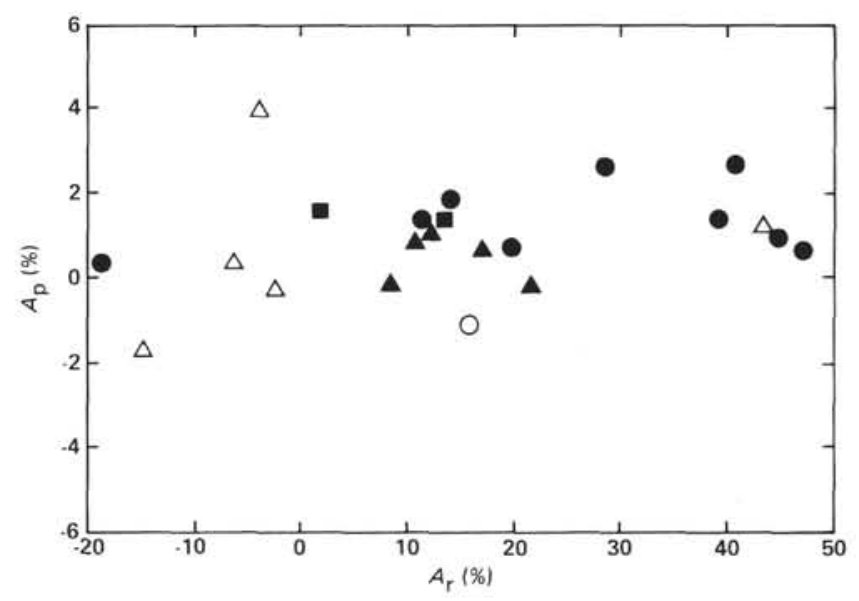

Figure 24. Compressional velocity anisotropy $\left(A_{\mathrm{p}}\right)$ versus resistivity anisotropy $\left(A_{\mathrm{r}}\right)$. Symbols as in Figure 3.

velops anisotropies with sound velocity and electrical conductivity greater parallel to the seafloor than normal to it. This is the situation predicted if the collapse of the "house of cards" clay mineral structure, because of increased overburden pressure, is the main cause of the acoustic and electrical response of the brown pelagic clay sediment.

Throughout the discussion we have alluded to the different properties of the brown pelagic clay unit at Site 581. It has a higher water content, lower density, lower compressional-wave velocity, and lower resistivity than would be anticipated for its depth of burial. The reasons for this anomalous situation are not clear. There does not appear to be a substantially large difference in the lithology of this unit from location to location, although Hole 581 brown pelagic clay may be less silty than the brown pelagic clays of Holes 576 and 578. It is possible that because of the high depositional rate of the overly- 
ing biosiliceous muds in Hole 581, the expulsion of water from the underlying brown pelagic clay was not able to keep pace with pressure loading. The brown pelagic clay pore waters may be supporting some of the weight of the overlying sediments. It is also possible that the change in drilling technique between Holes 576 and 578 (HPC) and Hole 581 (conventional rotary drilling) influenced the properties of Site 581 brown pelagic clay differently than the brown pelagic clay from Sites 576 and 578. Whatever the cause, the apparent different physical properties of Site 581 brown pelagic clay complicate the picture relating burial depth, porosity, and density to resistivity and elastic properties.

\section{CONCLUSIONS}

The measurement of a number of properties (mineralogy, chemistry, bulk density, acoustic velocity, and electrical resistivity) on the same samples has allowed us to draw the following conclusions concerning (1) the depth variations of these properties at Sites 576,578 , and 581 and (2) the role of composition and diagenesis in determining the physical properties and acoustic and electrical response of pelagic clays.

1. A relatively homogeneous brown pelagic clay unit of similar age can be identified at all three sites studied. This unit is characterized by a high clay/quartz ratio, a high trace-metal content, generally a high content of smectite-rich mixed-layer illite/smectite, and the presence of palygorskite in many samples.

2. These characteristics reflect both the diminished importance of detrital input and an enhanced diagenetic signal in the brown pelagic clay unit relative to overlying muds.

3. Variations in bulk density, acoustic velocity, and electrical resistivity primarily reflect the effects of compaction and loss of porosity accompanying burial.

4. Resistivity, especially in the vertical direction, varies with clay/quartz ratio. The trend in the brown pelagic clay unit is separate and approximately parallel to that defined by overlying muds. The separate trends cannot be explained by any single factor (depth, porosity, mineralogy, or chemistry), but must reflect a combination of factors that influence resistivity.

5. Other than the influence of clay/quartz ratio on resistivity, no correlations of mineralogy or chemistry with physical, acoustic, or electrical properties were noted. It is likely that the observed compositional variations are not large enough to generate a response in these properties, or such response is overshadowed by the dominant effects of compaction (porosity loss) and textural change (clay/quartz ratio).

6. Development of preferred orientation of clay platelets upon burial and loss of porosity and water content during compaction result in development of anisotropy in both acoustic and electrical properties with depth.

\section{ACKNOWLEDGMENTS}

We gratefully acknowledge DSDP and the scientists of Leg 86 for permitting us early access to samples. An early draft of the manuscript was improved because of the reviews of James Hein, Seymour Schlanger, and Audrey Wright. We thank Carol Koyanagi and Pat Sexton for typing the manuscript. This research was supported by ONR
N00014-82-C-0380. Hawaii Institute of Geophysics Contribution No. 1599.

\section{REFERENCES}

Anderson, J. U., 1963. An improved pretreatment for the mineralogical analysis of samples containing organic matter. Clays Clay Miner., 10:380-388.

Archie, G. E., 1942. The electrical resistivity log as an aid in determining some reservoir characteristics. Trans. Am. Inst. Min., Metall. Pet. Eng., 146:54-62.

1950. Introduction to petrophysics of reservoir rocks. Am. Assoc. Pet. Geol. Bull., 34:943-961.

Birch, F., 1960. The velocity of compressional waves in rocks to $10 \mathrm{ki}-$ lobars, Part 1. J. Geophys. Res., 65:1083-1103.

1961. The velocity of compressional waves in rocks to 10 kilobars, Part 2. J. Geophys. Res., 66:2199.

Biscaye, P. E., 1965. Mineralogy and sedimentation of Recent deepsea clay in the Atlantic Ocean and adjacent seas and oceans. Geol. Soc. Am. Bull., 76:803-832.

Boyce, R. E., 1968. Electrical resistivity of modern marine sediments from the Bering Sea. J. Geophys. Res., 73:4759-4766.

1976. Sound velocity-density parameters of sediment and rock from DSDP drill Sites $315-318$ on the Line Islands Chain, Manihiki Plateau, and Tuamotu Ridge in the Pacific Ocean. In Schlanger, S. O., Jackson, E. D., et al., Init. Repts. DSDP, 33: Washington (U.S. Govt. Printing Office), 695-728. 1980. Determination of the relationships of electrical resistivity, sound velocity, and density/porosity of sediment and rock by laboratory techniques and well logs from Deep Sea Drilling Project Sites 415 and 416 off the coast of Morocco. In Lancelot, Y., Winterer, E. L., et al., Init. Repts. DSDP, 50: Washington (U.S. Govt. Printing Office), 305-318.

, 1981. Electrical resistivity, sound velocity, thermal conductivity, density-porosity, and temperature, obtained by laboratory techniques and well logs: Site 462 in the Nauru Basin of the Pacific Ocean. In Larson, R. L., Schlanger, S. O., et al., Init. Repts. $D S D P, 61$ : Washington (U.S. Govt. Printing Office), 743-761.

Brewster, G. R., 1980. Effect of chemical pretreatment on x-ray powder diffraction characteristics of clay minerals derived from volcanic ash. Clays Clay Miner., 28:303-310.

Couture, R. A., 1977. Composition and origin of palygorskite-rich and montmorillonite-rich zeolite-containing sediments from the $\mathrm{Pa}$ cific Ocean. Chem. Geol., 19:113-130.

Elderfield, H., 1976. Hydrogenous material in marine sediments; excluding manganese nodules. In Riley, J. P., and Chester, R. (Eds.), Chemical Oceanography (Vol. 5, 2nd ed.): New York (Academic Press), 137-215.

Hamilton, E. L., 1971. Elastic properties of marine sediments. J. Geophys. Res., 76:579-604.

1978. Sound velocity-density relations in seafloor sediments and rocks. J. Acoust. Soc. Am., 63:366-377.

Hamilton, E. L., and Bachman, R. T., 1982. Sound velocity and related properties of marine sediments. J. Acoust. Soc. Am., 72: 1891-1904.

Hamilton, E. L., Bachman, R. T., Berger, W. H., Johnson, T. C., and Mayer, L. A., 1982. Acoustic and related properties of calcareous deep-sea sediments. J. Sediment. Petrol., 52:733-753.

Hein, J. R., and Scholl, D. W., 1978. Diagenesis and distribution of late Cenozoic volcanic sediment in the southern Bering Sea. Geol. Soc. Am. Bull., 89:197-210.

Hein, J. R., Scholl, D. W., and Gutmacher, C. E., 1976. Neogene clay minerals of the far NW Pacific and southern Bering Sea. In Bailey, S. W. (Ed.), A.I.P.E.A. Proceedings, 1975 International Clay Conference, Mexico City: Illinois (Applied Publishing), pp. 71-80.

Hoffman, J., 1976. Regional metamorphism and K-Ar dating of clay minerals in Cretaceous sediments of the Disturbed Belt of Montant [Ph.D. dissert.]. Case Western Reserve University, Cleveland.

Keller, G. V., 1966. Electrical properties of rocks and minerals. In Clark, S. P. Jr., (Ed.), Handbook of Physical Constants (revised ed.). Mem. Geol. Soc. Am., 97:553-577.

Kermabon, A., Gehin, C., and Blavier, P., 1969. A deep-sea electrical resistivity probe for measuring porosity and density of unconsolidated sediment. Geophysics, 34:554-571.

Manghnani, M. H., Schlanger, S. O., and Milholland, P. D., 1980. Elastic properties related to depth of burial, strontium content, 
and age and diagenetic stage in pelagic carbonate sediments. In Kuperman, W. A., and Jensen, F. B. (Eds.), Bottom Interacting Ocean Acoustics: New York (Plenum Press), pp. 44-51.

Mann, U., and Fischer, K., 1982. The triangle method-semiquantitative determination of clay minerals. J. Sediment. Petrol., 52: 654-657.

Mann, U., and Müller, G., 1979. X-ray mineralogy of Deep Sea Drilling Project Legs 51 through 53, Western North Atlantic, In Donnelly, T., Francheteau, J., Bryan, W., Robinson, P., Flower, M., Salisbury, M., et al., Init. Repts. DSDP, 51, 52, 53, Pt. 2: Washington (U.S. Govt. Printing Office), 721-729.

Mehra, O. P., and Jackson, M. L., 1960. Iron oxide removal from soils and clays by a dithionite-citrate system buffered with sodium bicarbonate. Clays Clay Miner., 7:317-327.

Olhoeft, G. R., 1980. Initial report of the petrophysics laboratory. 1977-1979 Addendum, U.S. Geol. Survey Open File, Rept. 80-522.

Press, F., 1966. Seismic velocities. In Clark, S. P., Jr. (Ed.), Handbook of Physical Constants (revised ed.). Mem. Geol. Soc. Am., 97:195-218.
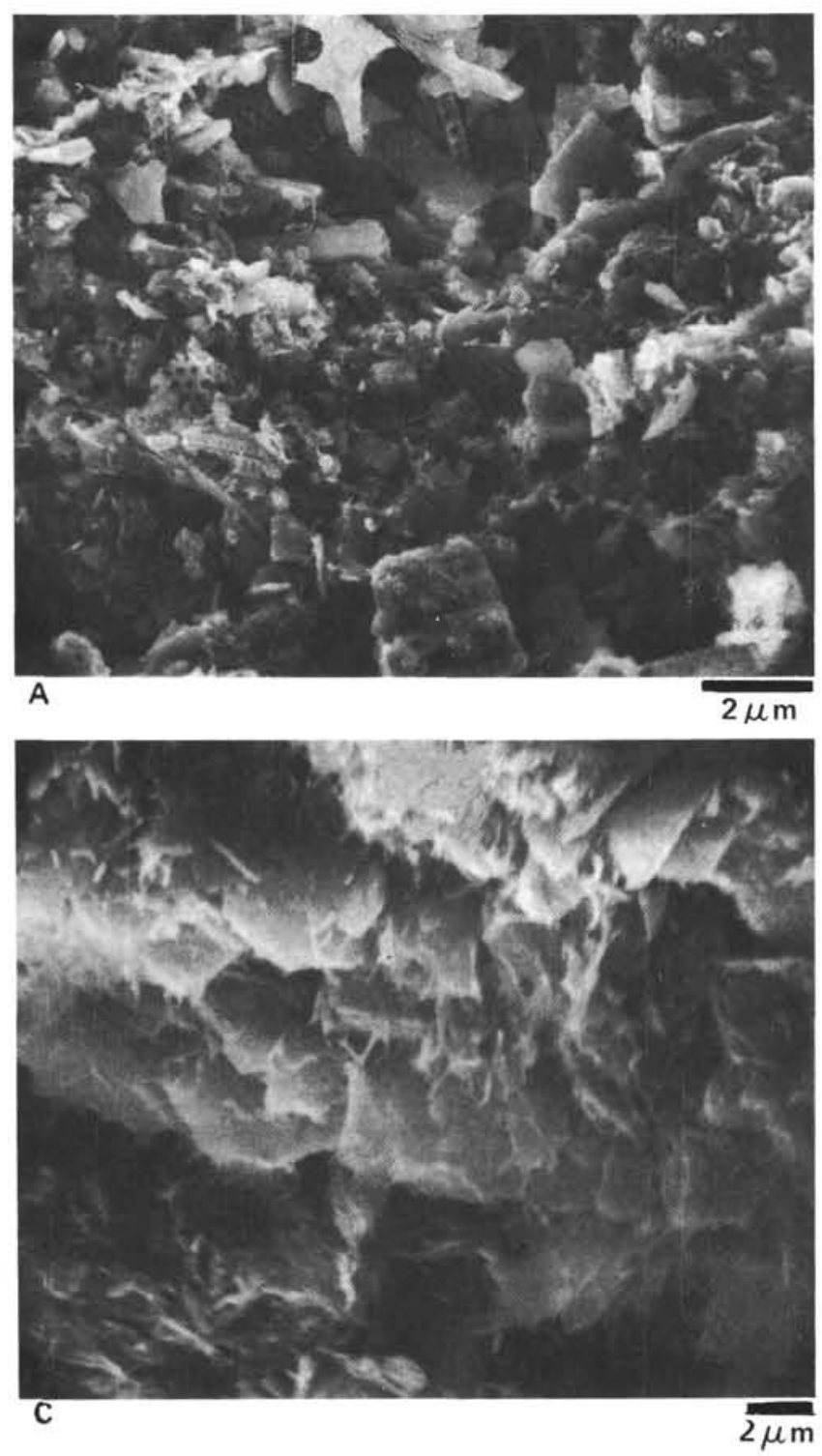

Reynolds, R. C., and Hower, J., 1970. The nature of interlayering in mixed-layer illite-montmorillonites. Clays Clay Miner., 18:25-36.

Risvet, B. L., 1978. Reverse Weathering Reactions within Recent Nearshore Marine Sediments, Kaneohe Bay, Oahu. Test Directorate Field Command, Kirtland AFB, New Mexico.

Schlumberger, 1958. Introduction to Schlumberger Well Logging (Schlumberger Document No. 8): New York (Schlumberger Well Surveying Corp.).

Schultz, L. G., 1964. Quantitative interpretation of mineralogical composition from x-ray and chemical data for the Pierre Shale. Geol. Surv. Prof. Pap. U.S., 391-C:1-31.

Vallier, T. L., and Kidd, R. B., 1977. Volcanogenic sediments in the Indian Ocean. In Heirtzler, J. R. (Ed.), Indian Ocean Geology and Biostratigraphy: Washington (Am. Geophys. Union), pp. 87-118.

Date of Initial Receipt: 26 April 1984

Date of Acceptance: 26 August 1984
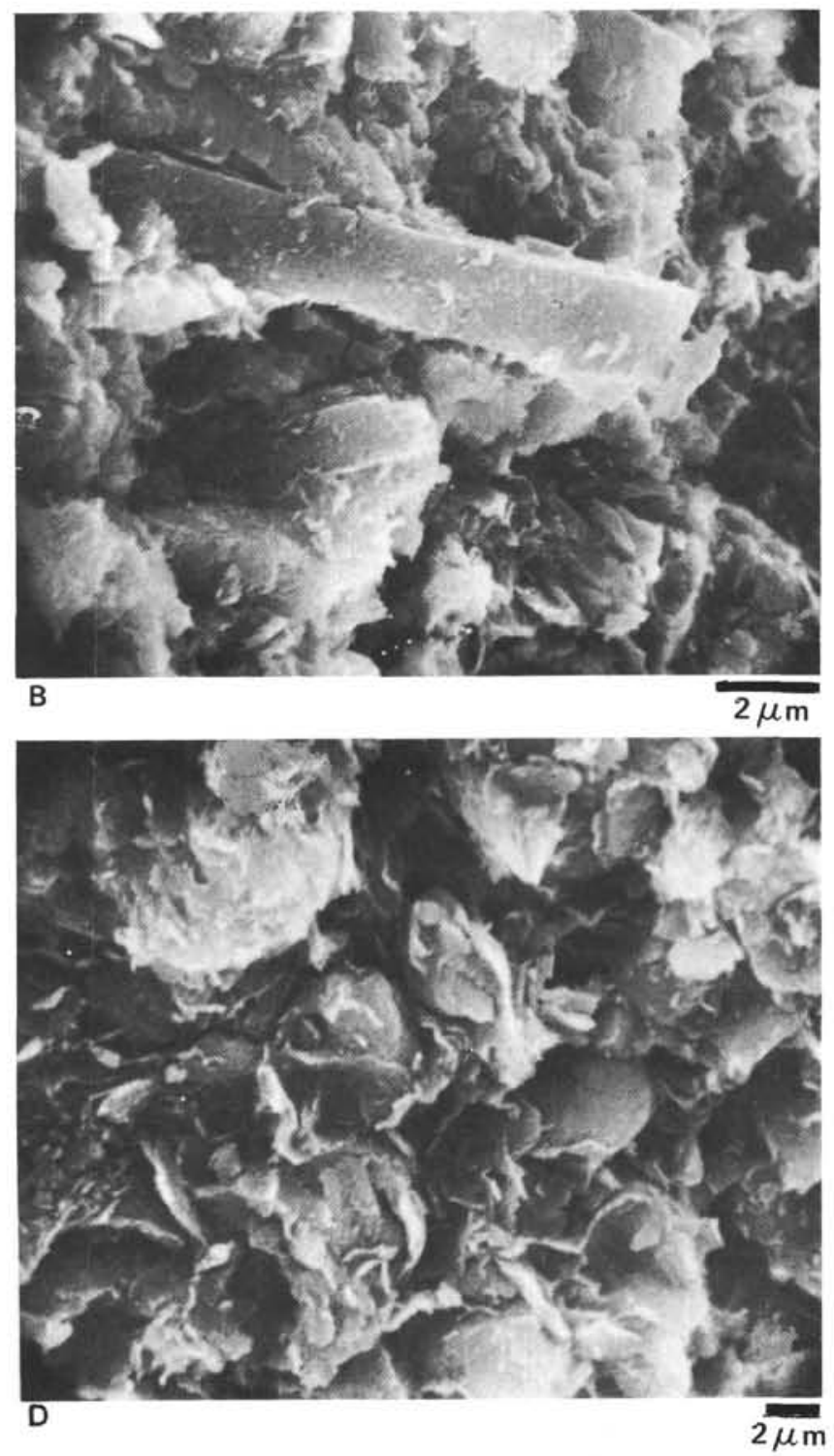

Plate 1. Scanning electron photomicrographs of pelagic clay textures. A. Smectite (Sample 576-8-6, 81-84 cm). B. Fibrous palygorskite (Sample 578-18-3, 38-45 cm). C. Authigenic phillipsite crystal (Sample 576-5-6, 18-25 cm). D. Opaline silica-rich clay (Sample 576-8-1, 98-105 cm). 